\title{
Epithelial junctions, cytoskeleton, and polarity
}

Gabriella Pásti and Michel Labouesse ${ }^{\mathcal{S}}$

Department of Development and Stem Cells, IGBMC, CNRS UMR7104/ INSERM U964/

Université de Strasbourg, Illkirch, France

\section{Table of Contents}

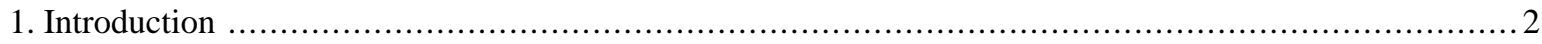

2. Approaches and tools to characterize junctional and cytoskeletal components ............................

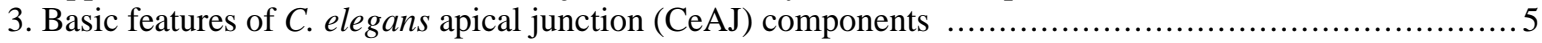

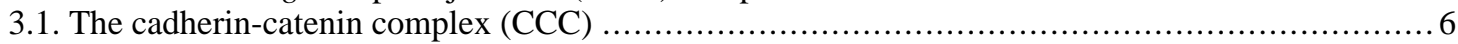

3.2. The DLG-1/AJM-1 complex (DAC) ........................................................ 6

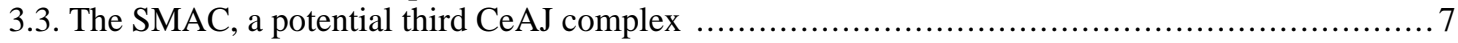

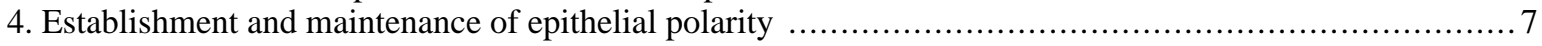

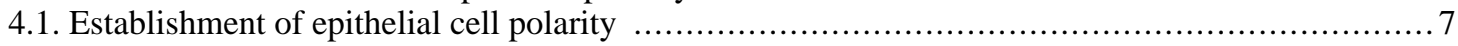

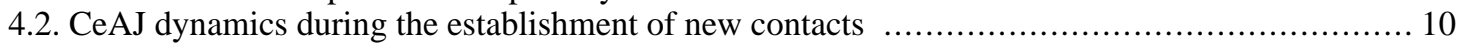

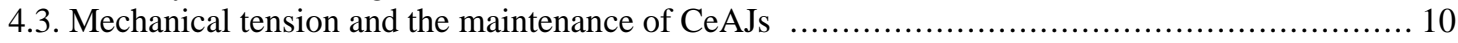

4.4. Membrane composition and trafficking in the maintenance of epithelial polarity $\ldots \ldots \ldots \ldots \ldots \ldots . . . . .10$

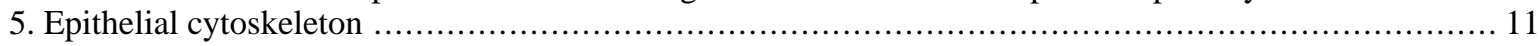

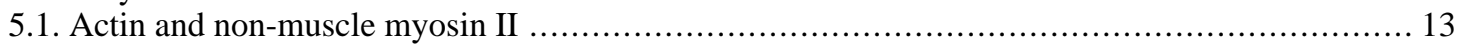

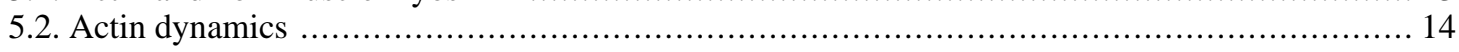

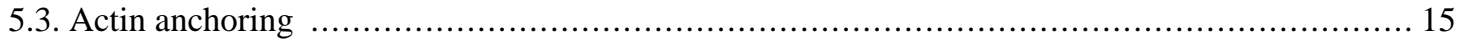

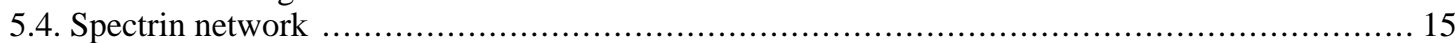

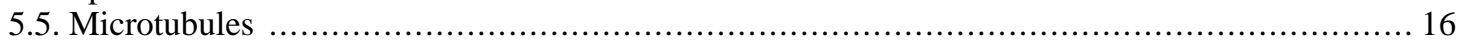

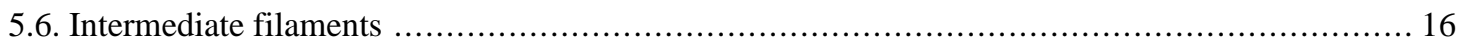

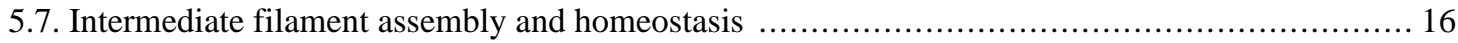

6. CeHDs and Fibrous organelles: cell-extracellular matrix junctions and mechanical coupling ............. 18

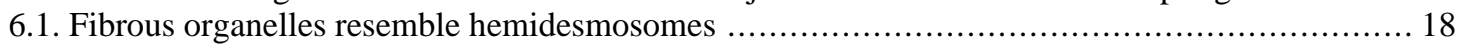

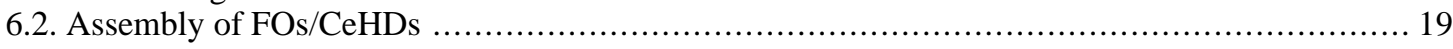

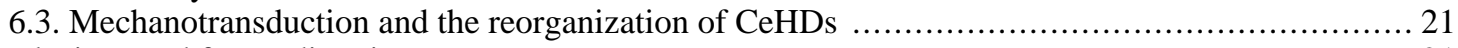

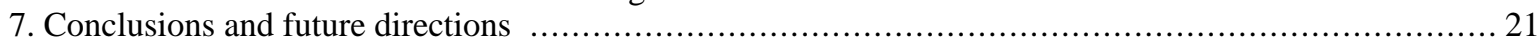

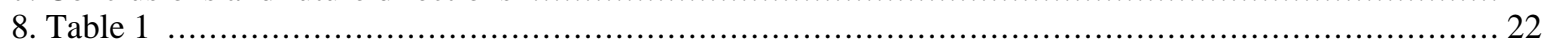

\footnotetext{
*Edited by Don Moerman. Last revised December 4, 2013. Published November 4, 2014. This chapter should be cited as: Pásti, G. and Labouesse, M. Epithelial junctions, cytoskeleton, and polarity (November 4, 2014), WormBook, ed. The C. elegans Research Community, WormBook, doi/10.1895/wormbook.1.56.2, http://www.wormbook.org.

Copyright: ( 2015 Gabriella Pásti and Michel Labouesse. This is an open-access article distributed under the terms of the Creative Commons Attribution License, which permits unrestricted use, distribution, and reproduction in any medium, provided the original author and source are credited.

${ }^{\S}$ To whom correspondence should be addressed. E-mail: lmichel@igbmc.fr
} 


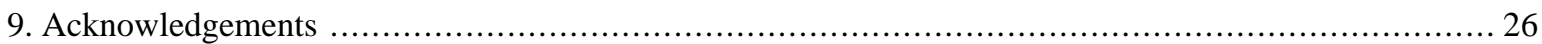

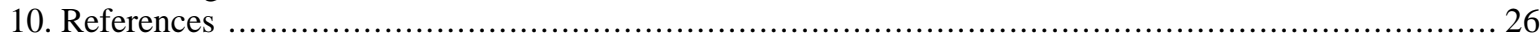

\begin{abstract}
A distinctive feature of polarized epithelial cells is their specialized junctions, which contribute to cell integrity and provide platforms to orchestrate cell shape changes. This chapter discusses the composition, assembly and remodeling of $C$. elegans cell-cell (CeAJ) and hemidesmosome-like cell-extracellular matrix junctions (CeHD), proteins that anchor the cytoskeleton, and mechanisms involved in establishing epithelial polarity. Major recent progress in this area has come from the analysis of mechanisms that maintain cell polarity, which involve lipids and trafficking, and on the impact of mechanical forces on junction remodeling. This chapter focuses on cellular, rather than developmental, aspects of epithelial cells.
\end{abstract}

\title{
1. Introduction
}

Two seemingly opposite features characterize epithelial cells. On one hand, their cell-cell adhesion junctions organize epithelial tissues as strong barriers; on the other hand, cell-cell junctions need to be remodeled through cytoskeleton-generated forces during embryonic morphogenesis.

Since the first version of this chapter more than eight years ago, Epithelial junctions and attachments, our general understanding of epithelial biology has evolved in two main directions. First, a few novel adhesion components have been identified and characterized. Second and foremost, we better grasp how cell polarity and mechanical tension impact on junction remodeling. The structure of this chapter will reflect this evolution. We first introduce the main cell-cell junction components present in epithelia. We then consider the mutual relationship between cell adhesion and epithelial polarity. In the second part, we introduce the actin, IF, and microtubule cytoskeleton and discuss the crosstalk between cell adhesion and cytoskeleton dynamics. Last, we introduce the hemidesmosome-like cell-extracellular matrix junctions that provide a link between muscles and the cuticle, and discuss the dynamic aspects of hemidesmosome remodeling.

As in Epithelial junctions and attachments, we will focus on cellular aspects of epithelial junctions, and will refer the reader to recent reviews for a more comprehensive discussion of the topic (Zhang and Labouesse, 2010; Baum and Georgiou, 2011; Loveless and Hardin, 2012), to other WormBook chapters for morphogenetic aspects (Epidermal morphogenesis; The C. elegans pharynx: a model for organogenesis; The C. elegans intestine), or for a discussion of extracellular matrix components (Basement membranes; The cuticle). For a general presentation and anatomy of C. elegans epithelia - the epidermis and seam cells, epithelial cells of the pharynx and buccal cavity, the intestinal and rectal cells, the excretory system-we refer the reader to WormAtlas (www.wormatlas.org). The status of sensory neuron support cells is hybrid, they are often considered as glial (Bacaj et al., 2008), yet they make cell-cell junctions including CeAJ markers discussed below.

\section{Approaches and tools to characterize junctional and cytoskeletal components}

Various approaches have been used over time to identify junctional/cytoskeletal components. Francis and Waterston pioneered this area by raising monoclonal antibodies (mAbs) against insoluble membrane-associated embryonic extracts (Francis and Waterston, 1985; Francis and Waterston, 1991). Some of these mAbs turned out to recognize junctional components (LET-805/myotactin, AJM-1, VAB-10A, recognized by MH46, MH27, and MH5 mAbs, respectively) or intermediate filaments (IFs; MH4, and MH33 mAbs), and provided critical entry points to start investigating junction assembly and morphogenesis (Priess and Hirsh, 1986; Podbilewicz and White, 1994; Chanal and Labouesse, 1997; Terns et al., 1997; Williams-Masson et al., 1997; Hresko et al., 1999; Carberry et al., 2012).

Since then, most genes encoding junctional or cytoskeletal components have been identified by genetic means in screens for larval defects (sma-1, тиа-3, тиа-6, vab-10, erm-1), embryonic elongation defects (hmr-1, hmp-1, hmp-2, spc-1, zen-4, mup-4, pat-12), and variably penetrant sub-lethal body morphology defects (vab-10, ifb-1, $v a b-19, v a b-9)$, as well as RNAi enhancer screens starting from hypomorphs (zoo-1, magi-1, unc-34, srgp-1, unc-94, jac-1, pak-1), and chromosomal deficiency screens (let-413, vab-10). A few additional components were identified through protein-protein screens (EPS-8). With some exceptions (let-805/myotactin, ajm-1, pat-12), these genes turned out to encode proteins with clear vertebrate or insect homologues (see Table 1 in Section 8; Figure 1). Fluorescent protein fusions are now increasingly used to study the subcellular localization and kinetics of these proteins. 


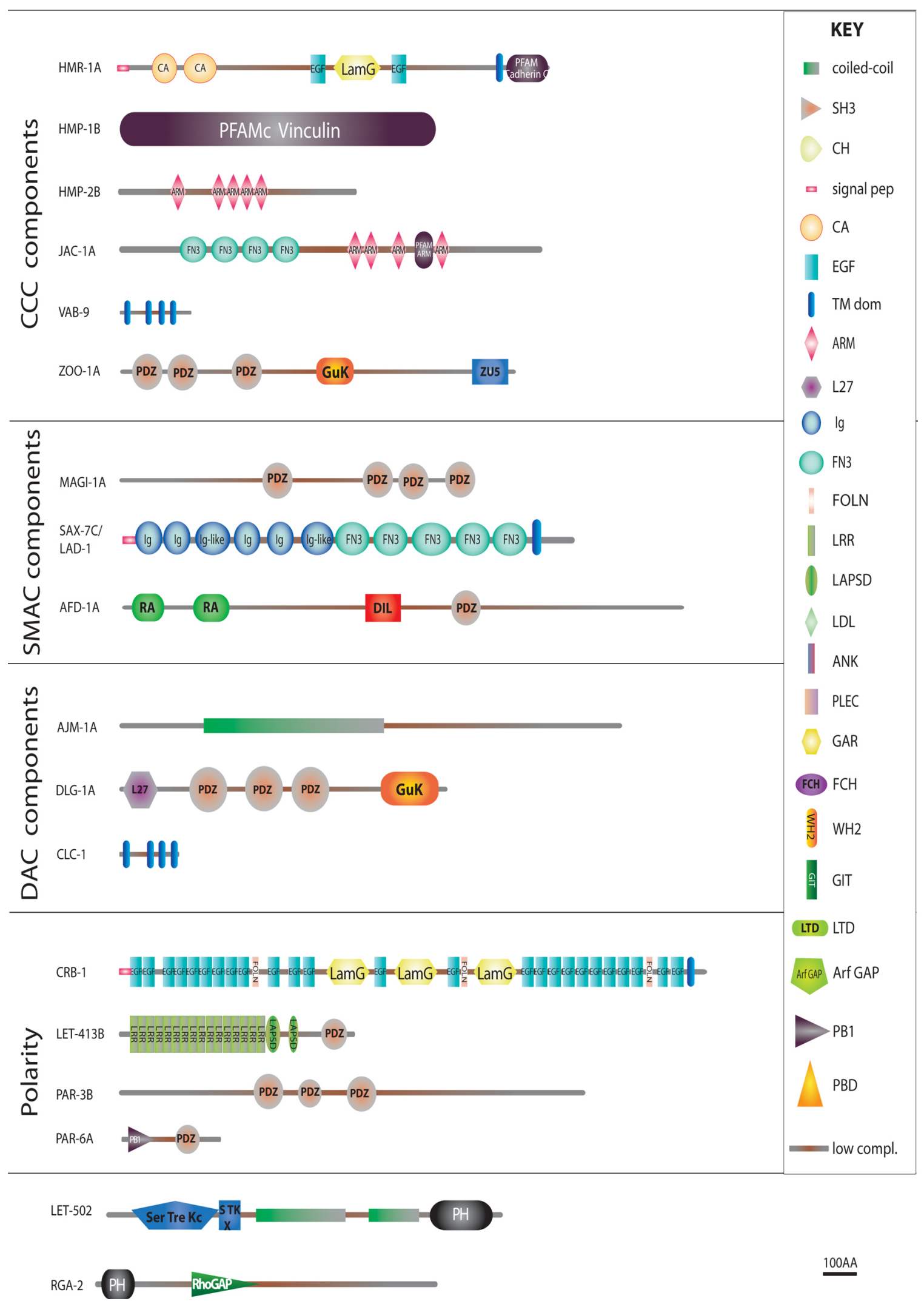

Figure 1. Structure of some epithelial junctional and cytoskeletal proteins. See below for legend. 


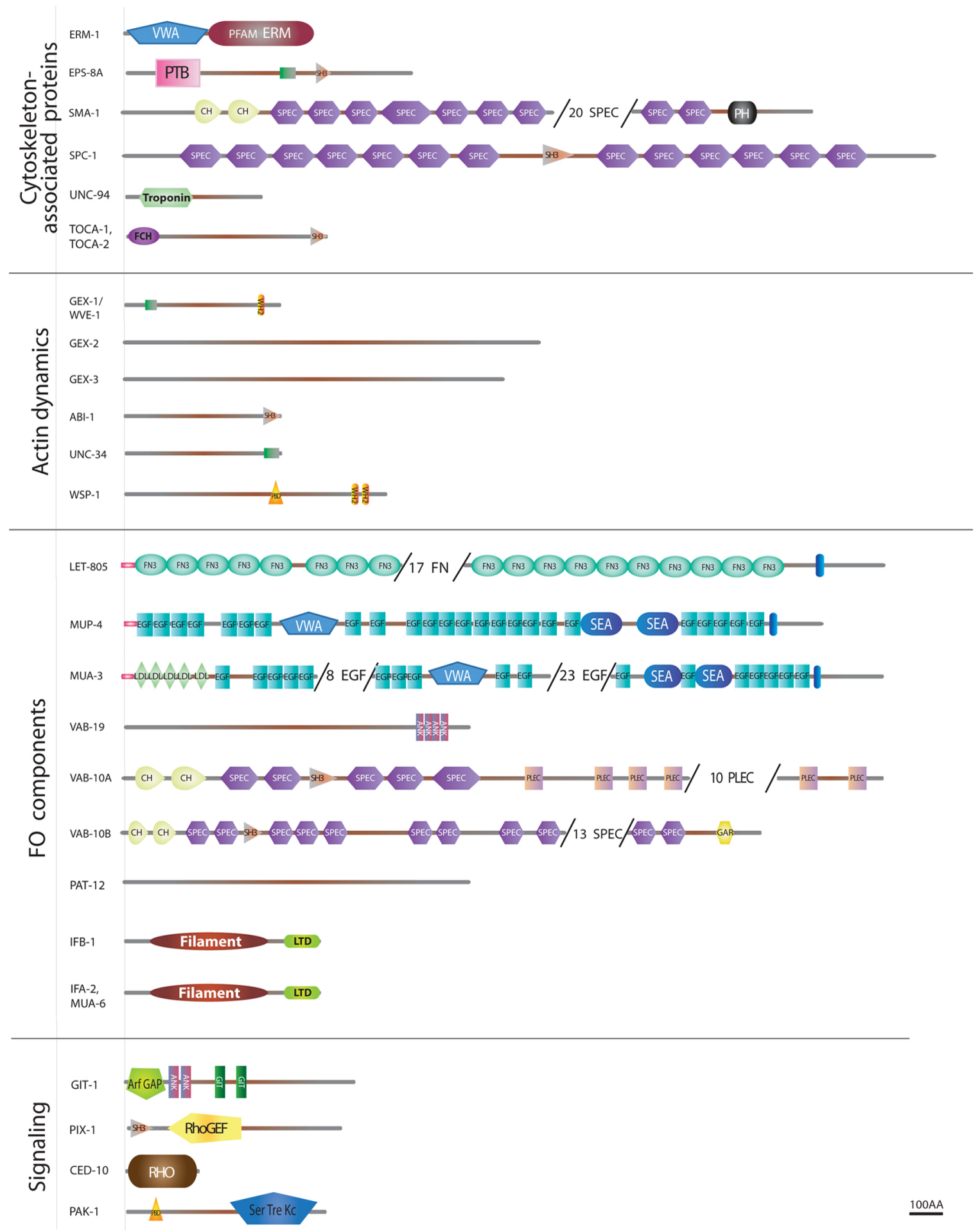

Figure 1 (continued). Structure of some epithelial junctional and cytoskeletal proteins. Schematic representation of the main epithelial-specific proteins that are further discussed in the text. Predictions were generated by the SMART software (smart.embl-heidelberg.de) for the longest existing isoform. To fit large proteins on the page, some repeats were omitted (numbers in parentheses). Proteins are grouped as in Table I according to their membrane domain or presumptive function. The key for domains is shown on the left, except for those big enough to use larger fonts, and refer to SMART or PFAM domains (see Table I). Other symbols: CCC, Cadherin/Catenin Complex; DAC, DLG-1/AJM-1 Complex; FO, Fibrous organelle; signal pep, signal peptide; SMAC, SAX-7/MAGI-1/AFD-1 complex; TM dom, transmembrane domain.

Below, we will not systematically describe the structure and domain composition of proteins listed in Figure 1 and Table 1 (Section 8), and invite readers to use it as a reference. 


\section{Basic features of $C$. elegans apical junction (CeAJ) components}

Despite apparent differences, $C$. elegans epithelial cells look similar to their vertebrate and fly counterparts (Knust and Bossinger, 2002) (Figure 2A). Transmission electron microscopy identifies a single electron-dense junction in C. elegans (Figure 2A'), whereas flies and vertebrates possess two electron-dense junctional complexes. Nevertheless, cellular and genetic analyses have established that worm epithelial cells do contain at least two molecularly and functionally distinct junctional complexes. These two complexes (the cadherin-catenin complex and the DLG-1/AJM-1 complex) together are commonly referred to as the CeAJ (C. elegans Apical Junction, Figure 2A).

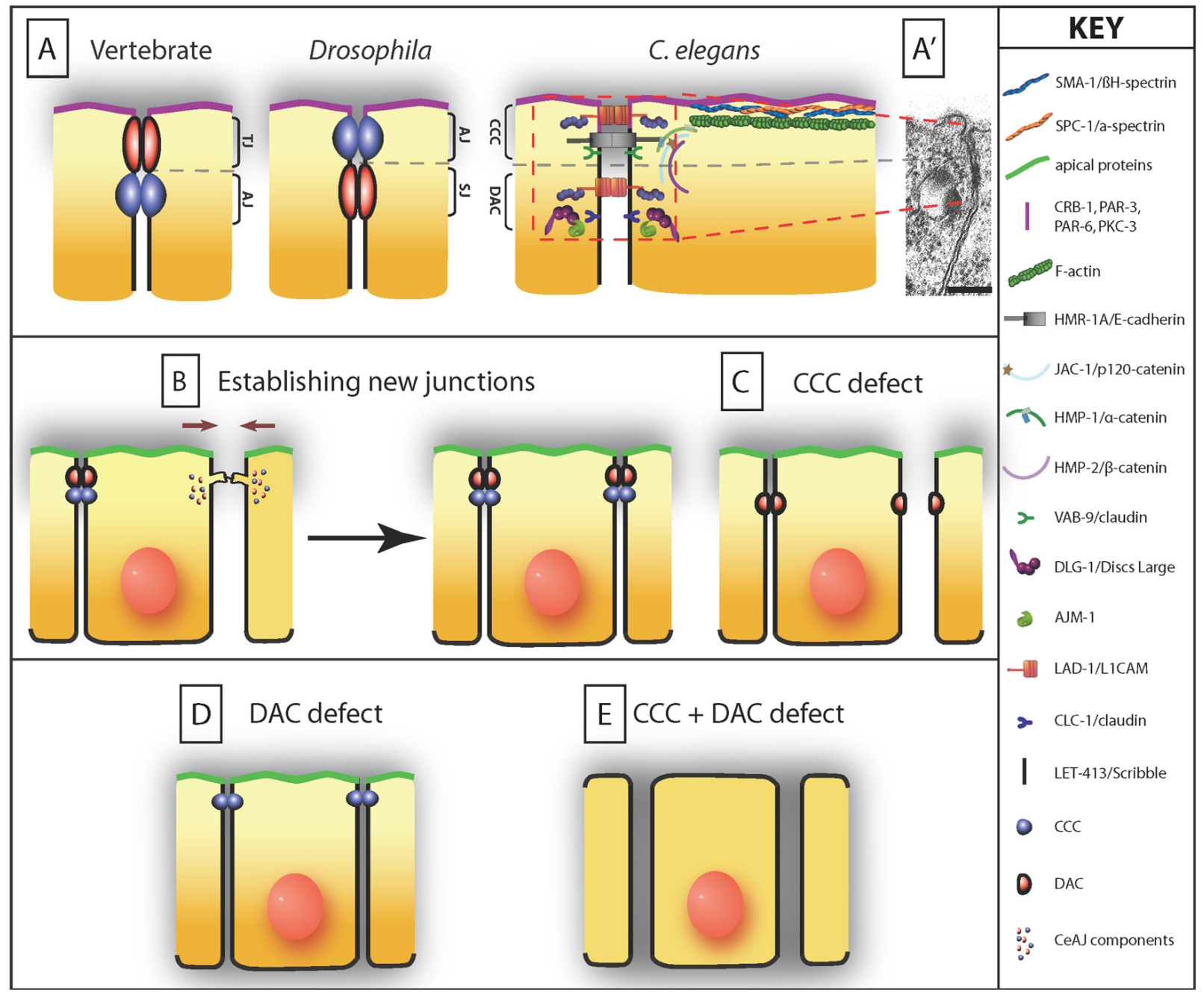

Figure 2. The CeAJ (C. elegans apical junction) and cell adhesion. (A) Schematic representation of known CeAJ components. As in vertebrates and Drosophila, $C$. elegans epithelial cells contain several adhesion complexes, the cadherin-catenin (CCC) and the DLG-1/AJM-1 (DAC) complexes. C. elegans is unique in three respects: (1) there is a single electron-dense area in the CeAJ (shown in A'; scale bar, 100 nm), (2) LET-413 does not colocalize with DLG-1 (as its homologue Scribble in Drosophila), and (3) SAX-7/MAGI-1/AFD-1, defining the SMAC, whose vertebrate homologues are part of the zonula adherens like the CCC, may have a yet distinct position from the CCC in C. elegans (it is shown at two positions). CeAJs from different epithelia contain the same set of proteins, although the classical claudin-like protein might differ in different tissues (CLC-1 in the pharynx, vulva and spermatheca; CLC-2 in the lateral epidermis). The DAC complex is likely to correspond to the electron-dense area of the CeAJ since immunogold staining experiments localize AJM-1 at the electron density, and removal of DLG-1 or AJM-1 compromises the electron dense area of the CeAJ (Köppen et al., 2001; McMahon et al., 2001). Note that the CCC mutants have not been examined by electron microscopy. (B) During ventral enclosure (facing arrows), ventral epidermal cells extend actin-rich filopodial extensions towards the ventral midline, where they must assemble a new CeAJ with their countralateral homologues through a cadherin/HMR-1-dependent recruitment of other CCC, and presumably DAC, components. (C) Ventral cells in zygotic hmr-1, maternal and zygotic hmp-2, or maternal and zygotic hmp-1 mutants can extend towards the ventral midline but fail to establish junctions. Adhesion between other cells remains normal in the absence of CCC components. (D) Cell-cell adhesion is not impaired in mutants lacking the DAC. Paracellular gate function is defective in animals lacking the claudin-like protein CLC-1, a putative DAC component in the pharynx, since pharyngeal cells fail to prevent a small fluorescent dye to leak between adjacent cells (grey material infiltrating between cells). (E) In animals lacking a CCC and a DAC protein (HMP-1 and DLG-1, or VAB-9 and DLG-1), cell adhesion is not maintained, causing epithelial cells to round up. 
In vertebrates and Drosophila, adherens junctions maintain cell-cell adhesion and anchor actin microfilaments. They include two distinct adhesion complexes: the Cadherin-Catenin complex and the Nectin-Afadin complex (Echinoid-Canoe in Drosophila). Tight junctions (also known as zonula occludens-they correspond to septate junctions in Drosophila) ensure a paracellular gate function. In addition, all these complexes contribute to the maintenance of cell polarity and act as signaling platforms (Tsukita et al., 1999; Takai et al., 2008; Laprise and Tepass, 2011). In this framework, we discuss below what is known about the cellular functions of the two CeAJ complexes.

\subsection{The cadherin-catenin complex (CCC)}

This complex is analogous in composition and function to the cadherin-catenin complex found in flies and vertebrates (Costa et al., 1998) (Figure 2A). The CCC includes homologues of the classical E-cadherin (HMR-1), $\beta$-catenin (HMP-2), $\alpha$-catenin (HMP-1), p120-catenin (JAC-1) (Costa et al., 1998; Pettitt et al., 2003; Simske et al., 2003); for further details, see (Loveless and Hardin, 2012). A distinctive feature of the C. elegans CCC is that it contains two proteins, VAB-9/BCMP1, a distant claudin superfamily member, and ZOO-1, a homologue of the zonula occludens $\mathrm{MAGuK}$ protein $\mathrm{ZO}-1$, which are related to tight junction components in vertebrates. However, neither VAB-9, which recruits ZOO-1, nor ZOO-1 itself appear essential for paracellular gate function (Simske et al., 2003; Lockwood et al., 2008). The CCC is thought to be the most apical complex within the CeAJ (Köppen et al., 2001; McMahon et al., 2001). As in other species, APR-1, the homologue of the $\beta$-catenin binding partner APC, might also be part of the CCC, since apr-1 null mutants display an embryonic phenotype reminiscent of the $h m r-1$ ventral enclosure defect (Hoier et al., 2000).

One difference between the vertebrate/insect CCC and its C. elegans counterpart is that vertebrates/insects have a unique $\beta$-catenin mediating both cell adhesion and Wnt signaling, whereas $C$. elegans has evolved four $\beta$-catenin homologues, among which only HMP-2 mediates adhesion (Loveless and Hardin, 2012). In addition, $\alpha$-catenin does not make homodimers in vitro like its mammalian homologues (Kwiatkowski et al., 2010) and does not recruit vinculin, which in C. elegans is only found in muscles (Maiden et al., 2013).

Mutations in a single CCC component do not affect cell-cell adhesion among epidermal cells or intestinal cells, except as further discussed in Section 4.2, when new junctions are established during ventral enclosure.

\subsection{The DLG-1/AJM-1 complex (DAC)}

Two membrane-associated proteins define this complex, a membrane-associated guanylate kinase or MAGuK homologous to Drosophila Discs large (DLG-1), and a nematode-specific coiled-coil protein (AJM-1) (Bossinger et al., 2001; Firestein and Rongo, 2001; Köppen et al., 2001; McMahon et al., 2001) (Figure 2A). DLG-1 and AJM-1 form a bona fide complex since they interact in vitro and are mutually dependent on each other for proper localization in vivo (Köppen et al., 2001; McMahon et al., 2001; Segbert et al., 2004). DLG-1, the Disc-large homologue, has a function restricted to the DAC where it is essential to anchor the novel protein AJM-1, since the AJM-1 pattern remains punctate in the absence of DLG-1 (Bossinger et al., 2001; Firestein and Rongo, 2001; Köppen et al., 2001; McMahon et al., 2001). How DLG-1/AJM-1 is anchored to the membrane is not known. The claudin homologues CLC-1 or CLC-2 are required to maintain paracellular gate function in the pharynx, but depletion of either by RNA interference causes no apparent adhesion defects (Asano et al., 2003). Whether they might fulfill this anchoring role is unknown.

There is a strong sequence similarity between DLG-1 and Discs Large, which in Drosophila associates with septate junctions. Furthermore vacuoles appear in ajm- 1 and $d l g-1$ null mutants. This raises the possibility that the DAC could perform a role analogous to septate junctions in maintaining paracellular gating (Köppen et al., 2001). The observation that a low-molecular weight fluorescent dye can diffuse between pharyngeal cells in animals lacking CLC-1, a possible DAC component, provides direct support for this view (Asano et al., 2003) (Figure 2D).

Despite the absence of a detectable electron density in DLG-1 deficient embryos, or the presence of localized bubble-like separations between adjacent AJM-1 deficient cells, the absence of the DLG-1/AJM-1 complex does not cause major cell adhesion defects (Köppen et al., 2001; McMahon et al., 2001) (Figure 2D). 


\subsection{The SMAC, a potential third CeAJ complex}

Two recent papers have described a third possible CeAJ complex including the MAGuK homologue termed MAGI-1 (Stetak and Hajnal, 2011; Lynch et al., 2012). Both papers agree on the role of MAGI-1 in maintaining a separation between the DAC and CCC, and on having a mostly dispensable role, unless $\alpha$-catenin function is also partially compromised (Figure 2A). However, they disagree on the subcellular localization of MAGI-1: Stetak and Hajnal (2011) located MAGI-1 apical to the CCC; by contrast, Lynch et al. (2012) reported that MAGI-1 is between the DAC and the CCC. Both papers relied on confocal microscopy to position the MAGI-1 complex within the lateral membrane: as the distance between the DAC and CCC is at the limit of optical resolution, resolving this difference will require electron or super-resolution microscopy. Interestingly, Hardin and collaborators found that MAGI-1 is anchored by the transmembrane L1-CaM homologue SAX-7 and interacts with the adaptor protein AFD-1, an Afadin homologue (Lynch et al., 2012). Their results would potentially make a SAX-7/MAGI-1/AFD-1 complex (SMAC) function akin to the fly adhesion complex Echinoid/Canoe, except that Echinoid has fewer extracellular FN-like domains compared to SAX-7.

\section{Establishment and maintenance of epithelial polarity}

Apicobasal polarity is a prominent feature of epithelial cells characterized by the formation of specialized membrane regions, and is also thought to prevent cells from proliferation and tumorigenesis (Humbert et al., 2003). Its establishment results in the segregation of distinct membrane domains- the apical side forming the lumenal surface and the basolateral side connecting the adjacent cells to each other or to the basement membrane-separated by the specialized junctions discussed in the previous section. Junctions must be newly established during development in two very different instances: (1) when cells emerge from a non-polarized field of cells and differentiate as polarized epithelia during early development (e.g., the epidermis), and (2) when already polarized cells migrate to establish new contacts (e.g., during ventral enclosure). The assembly and positioning of adherens junctions involves different mechanisms in both instances. Once established, epithelial polarity must be maintained as the animal grows, which involves a third set of molecules and mechanisms. Below, we discuss each aspect sequentially.

\subsection{Establishment of epithelial cell polarity}

In Drosophila, the interplay between several scaffolding complexes-basolaterally the Scribble/Discs Large/Lethal giant larvae and Yurt/Coracle complexes, and apically the Bazooka/DmPAR-6/DaPKC and Crumbs/Stardust/PatJ complexes_-specify epithelial polarity (Knust and Bossinger, 2002; Nelson, 2003; Laprise and Tepass, 2011). In C. elegans, the establishment of epithelial polarity may rely on slightly different mechanisms and require multiple, probably redundant, cues. For instance, loss of CCC components does not affect epithelial polarity, nor cell adhesion as in other species (Costa et al., 1998). As in other species, the establishment of cell polarity in tubular organs and flat epithelial sheets appears to involve different processes (Nelson, 2003; Datta et al., 2011). In particular, in the intestine, the pharynx, and the excretory cell, the coalescence of small vesicles into a lumen might play a key role in establishing polarity (Leung et al., 1999 Berry et al., 2003).

\subsubsection{The Crb/Stardust/PatJ complex}

Homologues of Crb, Patj and Stardust exist in the C. elegans genome. Furthermore CRB-1 and EAT-20, the two Crb homologues, are present at the apical membrane; however, their absence alone does not affect epithelial polarity (Shibata et al., 2000; Bossinger et al., 2001; O. Bossinger, personal communication). However, their potential ancillary role in cell polarity can be revealed by the simultaneous knock-down of LET-413, HMP-1/ $\alpha$-catenin, and CRB-1 (Bossinger et al., 2001; Segbert et al., 2004).

\subsubsection{PAR proteins}

PAR-3, PAR-6 and PKC-3 are present at the apical membrane of all epithelial cells (Leung et al., 1999; Bossinger et al., 2001; Köppen et al., 2001; McMahon et al., 2001). Deciphering the function of PAR-3 and PAR-6 required an elegant strategy to rescue their early requirement in the zygote by tagging the proteins with the PIE-1 Zn-finger that mediates PIE-1 degradation in the soma (Nance et al., 2003; Totong et al., 2007; Achilleos et al., 2010; Feldman and Priess, 2012). The ensuing genetic analysis of PAR-3- or PAR-6-depleted embryos has revealed that intestinal and epidermal epithelia polarize through different mechanisms. 
In the epidermis, unexpectedly, CeAJ proteins assemble properly along the apico-lateral membrane in embryos lacking PAR-6 or PAR-3, which thus appear dispensable to specify epithelial polarity in this tissue (Totong et al., 2007; Achilleos et al., 2010). However, CeAJ fail to coalesce into mature junctions and remain fragmented in the plane of the tissue in PAR-6-deficient embryos (Totong et al., 2007) (Figure 3A-B). Surprisingly, epidermal CeAJs coalesce normally when PAR-3 is absent, although it is essential in the epidermis since PAR-3-deficient embryos fail to elongate (Achilleos et al., 2010). How PAR-6 achieves CeAJ coalescence is unknown. A role for PKC-3, if any, awaits investigation. Recent results suggest that PAR6 together with the small GTPase Cdc42 control trafficking events, in particular of junctional proteins in Drosophila epithelia (Balklava et al., 2007; Harris and Tepass, 2008). It will be interesting to determine whether the coalescence function of PAR-6 in C. elegans epithelia involves CDC-42-dependent trafficking events.

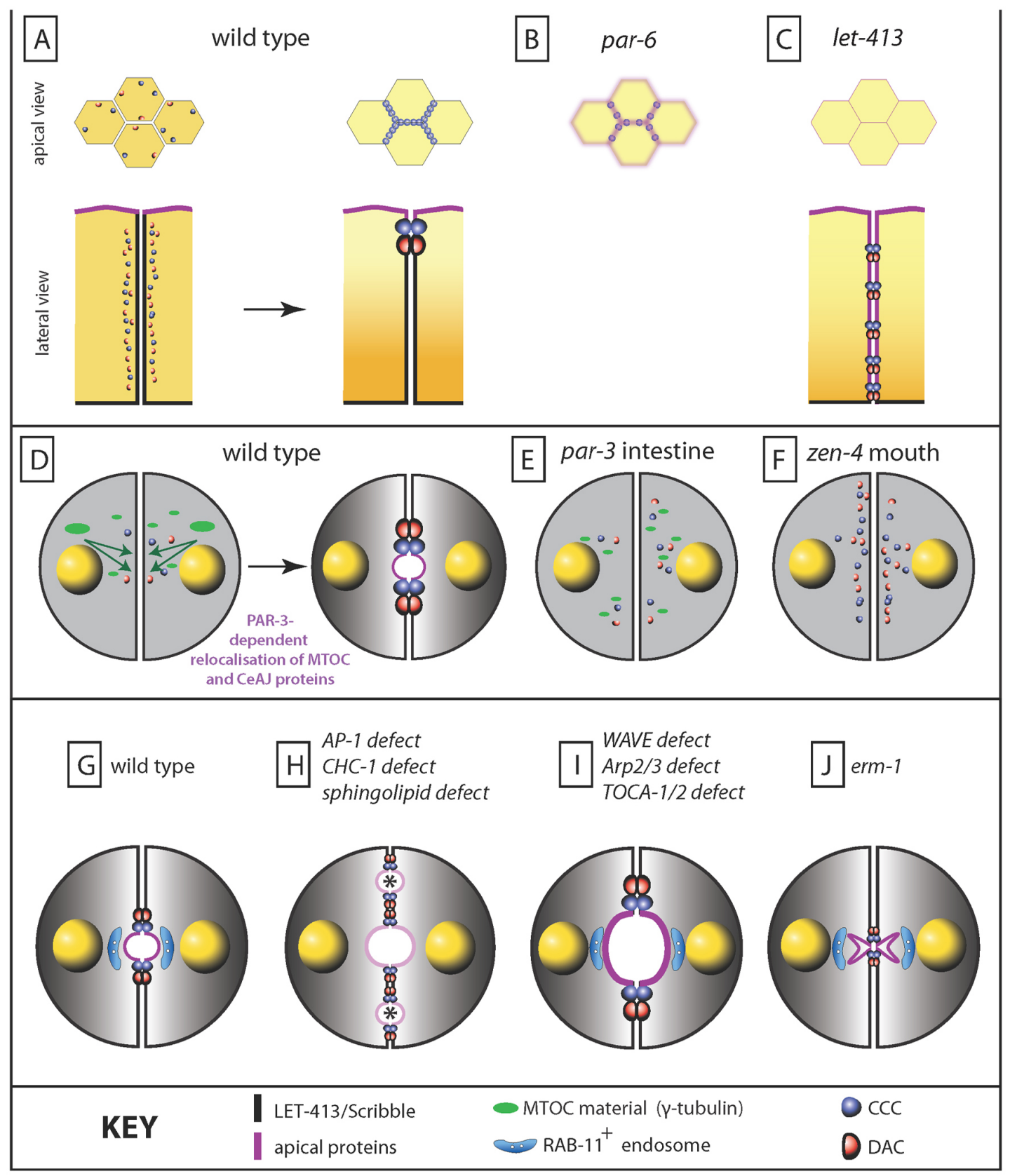

Figure 3. The establishment and maintenance of epithelial cell polarity. (A) Once born, epidermal cells rapidly establish CeAJs in a process that involves coalescence of junctional elements initially more spread along the lateral junction. Top, view at the apical surface; bottom, lateral view along the apico-basal axis. (B) In the epidermis and intestine of a maternal/zygotic par-6 mutant, junctions remain fragmented in the plane of the epithelium; it 
appears normal in the intestine along the apico-basal axis but has not been described for the epidermis (a lateral view was omitted due to the lack of the relevant information for the epidermis) (C) In a let-413 mutant, ectopic electron dense junctions are found along the lateral membrane, suggesting that apical coalescence of CeAJ components is defective. Furthermore, apical markers of the epidermis (CHE-14) and the intestine (PAR-3, PAR-6, IFB-2, ERM-1) become gradually mislocalized along the lateral membrane. (D) In the intestine, the establishment of epithelial polarity involves a handover of MTOC material from the centrosome to the apical surface in a process involving PAR-3. (E) In a par-3 mutant, this handover process is defective, and cell polarity is not established. (F) The establishment of epithelial polarity is also defective in the arcade cells of a zygotic zen-4 mutant. (G-H) Expansion of the intestine at later stages of development requires glycosphingolipids and the presence of the AP- 1 clathrin adaptor; RAB- $11^{+}$-endosomes play a key role in this process. Absence of sphingolipids or of AP-1 induces the formation of multiple lumens (asterisks), loss of the RAB- $11^{+}$-endosomes and partial loss of cell polarity. (I) A separate trafficking pathway, involving the Cdc42 effector TOCA-1/2 and the WAVE and Arp2/3 complexes, negatively regulates the amount of ERM-1 and indirectly controls junction homeostasis; in their absence, the lumen expands, in part due to a reduction of the DAC component DLG-1. (K) Loss of ERM-1 induces an opposite phenotype characterized by strong reduction of the lumen, loss of actin, and more DLG-1 at the CeAJ.

In the normal intestine, CeAJ components form puncta that progressively migrate to the midline and assemble subapical junctions (Leung et al., 1999) (Figure 3D). PAR-3 also forms puncta that move to the apical membrane together with puncta containing CCC components (Achilleos et al., 2010). In the absence of PAR-3, the PAR-6, PKC-3, and CCC puncta fail to form apically while basolateral markers spread around the cells, which thus fail to polarize (Achilleos et al., 2010) (Figure 3E). Interestingly, following the last round of intestinal cell division, core centrosome proteins ( $\gamma$-tubulin, CeGRIP) move apically in a process that requires PAR-3, microtubules, but not actin (Feldman and Priess, 2012) (Figure 3D-E). Furthermore, removal of centrosome material by laser ablation prevents junction assembly (Feldman and Priess, 2012). RNAi feeding in larvae also established that PAR-3 is required to specify polarity and to assemble the CeAJ in another tubular organ, the distal spermatheca (Aono et al., 2004). PAR-6 does not play a similar role, but instead, as in the epidermis, is essential to condense CCC puncta into a mature junction (Totong et al., 2007). A specific role for PAR-3 homologues in junction assembly, independent of PAR-6, has also been observed in Drosophila where PAR-3 acts as the earliest known landmark for AJ assembly (Laprise and Tepass, 2011). Hence, the establishment of epithelial polarity in tubular organs requires PAR-3, in conjunction with the MTOC at least in the intestine.

\subsubsection{Basolateral proteins required for $\mathrm{CeAJ}$ compaction and positioning}

In Drosophila, the basolateral proteins Scribble and Disc large counteract the activity of the apical polarity complexes to define the basal position of adherens junctions during the establishment of cell polarity (Elsum et al., 2012). The C. elegans Scrib and Dlg homologues have related functions, yet are not essential to establish polarity. Instead, the basolateral protein LET-413 acts to position the CeAJ by promoting its apical coalescence (Legouis et al., 2000; McMahon et al., 2001) (Figure 3A-C). In LET-413-deficient embryos, DLG-1, AJM-1 and HMP-1/ $\alpha$-catenin remain lateral, leading to lateral assembly of electron dense junctions (Legouis et al., 2000; McMahon et al., 2001), or reach their sub-apical position less efficiently (Köppen et al., 2001). Moreover, apical membrane markers progressively spread into the lateral membrane, suggesting that LET-413 acts to maintain polarity (Köppen et al., 2001; McMahon et al., 2001; Bossinger et al., 2004; Segbert et al., 2004). How would LET-413 act at the molecular level is unknown. LET-413 shows similarity with the Ras-interacting protein SUR-8 over the N-terminal leucine-rich repeats, which mediates basolateral localization. This suggests that LET-413 might interact with a yet unidentified small GTPase (Legouis et al., 2003). An unexpected cue as to the molecular process of junction compaction has recently come from the observation that loss of the inositol-triphosphate receptor ITR-1 or loss of the inositol polyphosphate 5-phosphatase IPP-5 can partially suppress let-413 mutations, indicating that it is calcium-sensitive (Pilipiuk et al., 2009). Intriguingly, ITR-1 interacts with non-muscle myosin II and is required for the migration of ventral epidermal cells during ventral enclosure (Walker et al., 2002; Thomas-Virnig et al., 2004), raising the possibility that myosin II is also involved in junction compaction.

It will be important in future studies to determine whether LET-413, PAR-6, and the SAX-7/AFD-1/MAGI-1 complex, which all contribute to compact the CCC and the DAC (Stetak and Hajnal, 2011; Lynch et al., 2012), act in the same or parallel processes. Finally, defining whether junction compaction in C. elegans is related to the mechanism involved in transporting Bazooka/PAR-3 apically during Drosophila cellularization (McKinley and Harris, 2012) should also be unraveled.

\subsubsection{Centralspindlin components and polarity}

The conventional kinesin ZEN-4/MKLP1 and the Rho GTPase-activating protein CYK-4, which form the so-called centralspindlin complex during cytokinesis (White and Glotzer, 2012), are required for epithelialization of arcade cells during pharynx tubulogenesis (Figure 3F). Normally, arcade cells undergo a mesenchymal-epithelial transition (MET) to assemble typical CeAJs, express PAR-3/PKC-3 at their apical membrane, and create a tube (Portereiko and Mango, 2001; Portereiko et al., 2004). In zen-4 or cyk-4 mutants, these steps fail, in part because the arcade microtubule and actin cytoskeletons are disorganized (Portereiko et al., 2004). Their requirement for epithelialization might be related to the MET process, since neither zen-4 nor cyk-4 mutants affect epithelial polarity in other tissues. 


\subsubsection{Junctions and polarity}

In Drosophila, there is an interplay between adherens junction components and proteins establishing epithelial polarity, especially with Bazooka/Par3 (Laprise and Tepass, 2011). In C. elegans, this interplay is either not as important or is masked by redundancy. For instance, contrary to what is observed in fly and mouse, loss of a single CCC component alone does not affect the establishment of epithelial polarity, but the simultaneous loss of a CCC and DAC components causes severe adhesion defects in the epidermis and the intestine (Figure 2E) (Simske et al., 2003; Segbert et al., 2004; L. McMahon and M. Labouesse, unpublished results). Similarly, the Moesin homologue ERM-1 is not essential for junction assembly or cell polarity, unless it is inactivated together with $\mathrm{hmr}$-1/E-cadherin, in which case the CeAJ is missing in many places (Van Fürden et al., 2004).

\subsection{CeAJ dynamics during the establishment of new contacts}

The establishment of novel contacts between already differentiated cells is a process that often occurs during development (e.g., C. elegans ventral enclosure, Drosophila dorsal closure, zebrafish epiboly or heart formation), and has been also described in tissue culture cells (Adams et al., 1998; Vasioukhin et al., 2000; Baum and Georgiou, 2011). C. elegans ventral enclosure has provided a powerful model to examine this question. Our purpose here is not to review the process of ventral enclosure (see Epidermal morphogenesis), but rather to outline how junction formation requires proper interaction with the actin cytoskeleton. In a seminal article, Jeff Hardin and collaborators found that the CCC complex is mobilized along actin-rich protrusions that prime the formation of novel contacts at the ventral midline (Raich et al., 1999) (Figure 2B). In embryos lacking maternal and zygotic CCC components (Costa et al., 1998), cells migrate ventrally but junctions are not established (Figure 2C). Interestingly, depletion of UNC-34/Enabled, which promotes filamentous actin polymerization, enhances the ventral sealing defects of a weak HMP-1/ $\alpha$-catenin mutant with reduced actin binding activity (Sheffield et al., 2007; Fleming et al., 2010). Hence, actin dynamics is essential to achieve the formation of novel junctions.

\subsection{Mechanical tension and the maintenance of CeAJs}

Junctions come under significant mechanical stress during embryonic morphogenesis. They can be torn apart, unless specific proteins ensure their mechanical stability to influence their composition and architecture through mechanisms that are just starting to be dissected (Huveneers and de Rooij, 2013). In C. elegans, starting from an enhancer screen against a weak mutation mapping to the actin-binding domain of HMP-1/ $\alpha$-catenin (Maiden et al., 2013), Jeff Hardin and his colleagues have identified several proteins required to stabilize junctions or their interactions with actin (Pettitt et al., 2003; Cox-Paulson et al., 2012; Lynch et al., 2012). In particular, the actin pointed-end capping protein UNC-94/tropomodulin acts in synergy with HMP-1/ $\alpha$-catenin to maintain the continuity of the junctional belt (Cox-Paulson et al., 2012). Its loss leads to junction fragmentation, shorter actin filaments, and defects in anchoring circumferential actin bundles (Cox-Paulson et al., 2012). Hardin and his collaborators speculate that long, tropomodulin-capped, junctional actin filaments might act like roots of a tree to prevent uprooting. While this model is appealing, there might be other alternatives since UNC-94 appears mainly expressed in seam cells, yet its loss induces a phenotype mainly when HMP-1 is altered in non-seam cells. Perhaps instead of a static vision of junctions and actin filaments, one should also consider a more dynamic one in which these entities flow and must be renewed, as established in Drosophila (Rauzi et al., 2010).

\subsection{Membrane composition and trafficking in the maintenance of epithelial polarity}

The lipid composition of the plasma membrane and polarized trafficking together influence epithelial polarity (Datta et al., 2011). For instance, phosphatidylinositol-3,4-phosphate (PIP2) enrichment at the apical membrane is essential for initial lumen formation and recruitment of the Cdc42/Par6 complex in 3D-models of MDCK cysts (Datta et al., 2011; Tepass, 2012). Another class of lipids, glycosphingolipids (GSLs), has been predicted to play a role in epithelial polarity more than twenty years ago (Simons and van Meer, 1988; Simons and Gerl, 2010), although their potential role has never been properly established in multicellular organisms. Likewise, the potential role of clathrin and its adaptors in mediating polarized trafficking has gained wide acceptance, although data in tissue culture cells have linked AP-1 and clathrin to basolateral trafficking (Folsch et al., 1999; Deborde et al., 2008; Mellman and Nelson, 2008). Recent work in C. elegans has revealed that glycosphingolipids and the AP-1 clathrin adaptor are important for maintaining cell polarity and sorting to the apical membrane once cells have been generated and polarity established (Zhang et al., 2011a; Shafaq-Zadah et al., 2012; Zhang et al., 2012) (Figure 3G-H). 
Performing an RNAi-based tubulogenesis screen, Zhang and colleagues identified several genes encoding enzymes of the GSL biosynthetic pathway, as well as the clathrin heavy chain CHC-1 and subunits of the AP-1 complex as mediators of an apical polarized transport (Zhang et al., 2011a; Zhang et al., 2012) (Figure 3H). In a separate study Shafaq-Zadah, studying the role of AP-1 coat components, also found that AP-1 is important for apical sorting (Shafaq-Zadah et al., 2012). Interestingly, depletion of these genes does not affect the initial establishment of epithelial polarity in the intestine, but induces a mislocalization of apical molecules including PAR-6, and the formation of lateral lumens only during late embryonic or larval development (Zhang et al., 2011a; Shafaq-Zadah et al., 2012; Zhang et al., 2012). Adding a mixture of various sphingolipids, including GSLs, can partially rescue the phenotype of let-767 or sptl-1 mutants, which affect the terminal steps of GSL synthesis (Zhang et al., 2011a). AP-1 is required to position CDC-42 apically and to maintain apical recycling RAB- $11^{+}$endosomes, suggesting that AP-1 might function at the level of this compartment (Shafaq-Zadah et al., 2012; Zhang et al., 2012) (Figure 3G-H). In part because mild alterations to both pathways produce strong synergistic effects, Göbel and coworkers proposed that clathrin/AP-1 functions in a direct apical sorting pathway that intersects with a sphingolipid-dependent sorting pathway (Zhang et al., 2012). Intriguingly, loss of the Lats-kinase homologue, WTS-1, also leads to ectopic intracellular intestinal lumens, a phenotype that can be partially suppressed by knocking down components of the exocyst complex (Kang et al., 2009). Since Wts/Lats acts in the Hippo pathway to maintain apical membrane identity in Drosophila, WTS-1 and the exocyst might potentially act in the same pathway as AP-1 and glycosphingolipids.

Interestingly, another study also found that the polarity factor PAR-5 and RAB- $11^{+}$recycling endosomes play a central role in maintaining intestinal polarity in larvae. When PAR-5 is depleted in larvae, RAB- $11^{+}$recycling endosomes become mis-positioned basolaterally along with actin patches in a process that depends on kinesin-1 and actin regulators (Winter et al., 2012). Altogether, the clathrin-dependent and sphingolipid raft-dependent trafficking pathways, seem to converge on recycling endosomes to control the maintenance of cell polarity. It is worth pointing out that, much like PAR-5 has roles to specify early embryonic polarity and then in larvae, GSLs might also play an earlier role in specifying epithelial polarity. Indeed, first the role of GSLs in larvae has been analyzed in mutants that also induce sterility, thus precluding the analysis of their potential role in defining early embryonic polarity. Second, loss of POD-1, an enzyme in the GSL biosynthesis pathway, induces polarity defects in the zygote (Rappleye et al., 1999).

A distinct trafficking process is required to maintain the proper positioning of the CeAJ relative to the intestinal lumen, which involves the Arp2/3 complex controlling branched actin formation, a Cdc42 effector named TOCA-1/2, and the Ezrin/Moesin homologue ERM-1 (Patel et al., 2008; Giuliani et al., 2009; Bernadskaya et al., 2011; Patel and Soto, 2013). When these proteins are absent the intestine lumen becomes wider, F-actin fails to accumulate to the same level apically, and there is a modest reduction of the DAC complex (Figure 3I). In Drosophila, the TOCA-1 homologue CIP4 controls E-cadherin endocytosis together with the polarity factors Cdc42/Par6 (Leibfried et al., 2008). How TOCA and Arp2/3 complex proteins help to maintain intestinal width has come from careful studies dissecting the role of the Arp $2 / 3$ in controlling early endocytosis and the morphology of early endosomes (Bernadskaya et al., 2011; Patel and Soto, 2013). These authors found that loss of the WAVE complex leads to increased ERM-1 levels apically and concomitantly a reduction of the junctional over cytoplasmic DLG-1 ratio. Consistent with these observations, loss of ERM-1 induces extreme narrowing of the intestinal lumen combined with lower DLG-1 level (Figure 3J). Since TOCAs bind to the WAVE complex, which acts as an activator of the ARP2/3 complex (Giuliani et al., 2009), it is likely that TOCA/-1/2, Arp2/3, and the WAVE complex act in the same pathway to control early endocytosis in the intestine.

\section{Epithelial cytoskeleton}

The three main cytoskeletal networks can be found in C. elegans (Figure 4), in contrast to Drosophila, which lacks intermediate filaments. Except for IFs (see below), the expression and potential functions of individual cytoskeletal proteins in epithelia have not yet been fully characterized. 


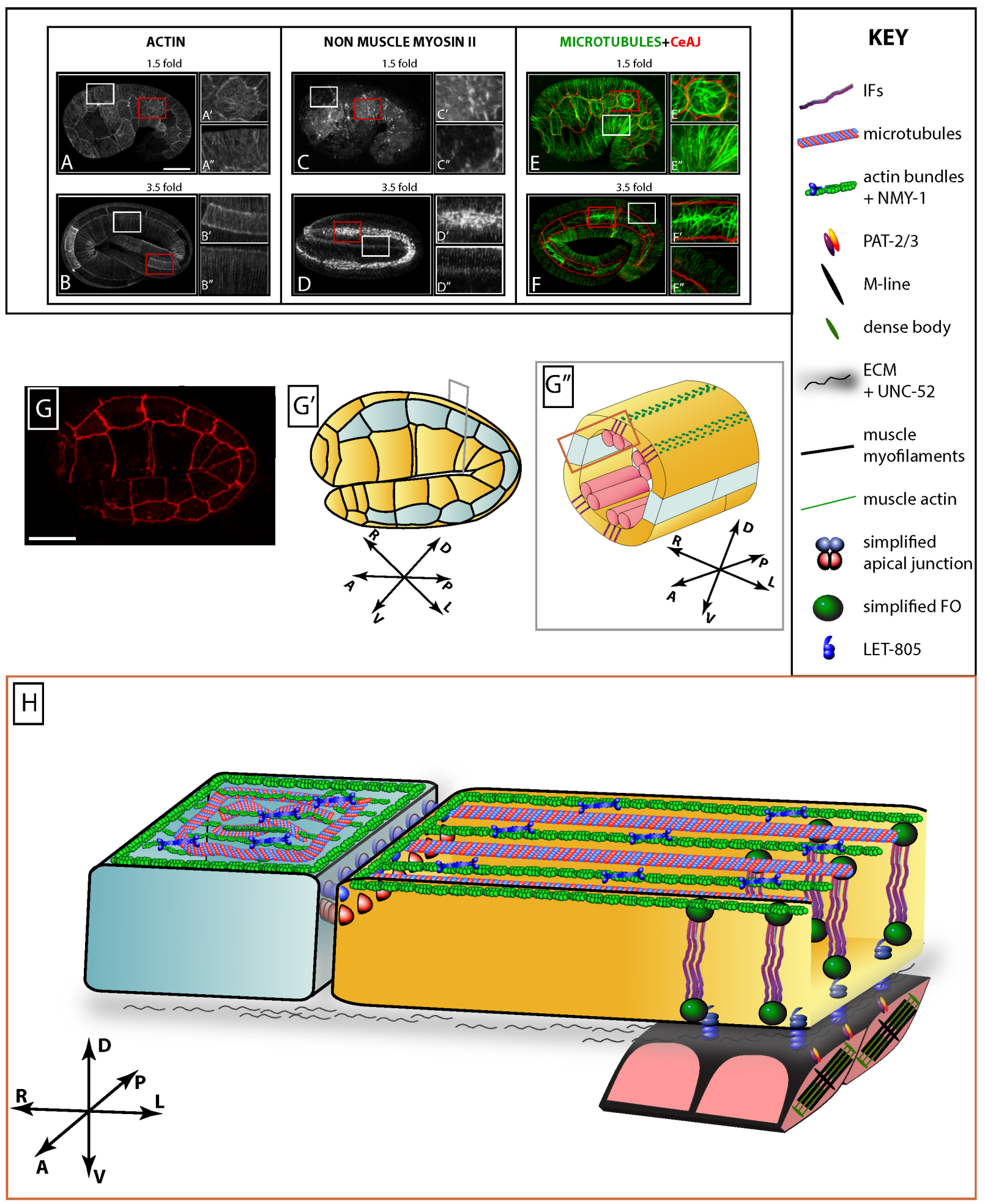

Figure 4. General anatomy of the epidermis. (A-B) Epidermal actin, as visualized with a GFP fused to the actin-binding domain of the protein VAB-10, (C-D) myosin II, as visualized with a GFP fused to the myosin regulatory chain MLC-4, and (E-F) microtubules (in green, visualized with GFP) and apical junctions (in red, visualized with DLG-1::RFP) at the 1.5-fold (E) and 3.5-fold stage (F), respectively. (A, C, E) 1.5-fold and (B, D, F) 3.5-fold stage embryos. (A'-F') and (A'-F') correspond to enlargements area boxed in red (seam cell) and white (non-seam cell), respectively. Note the regular actin organisation in the non-seam cell, the myosin II enrichment in seam cells, the regular distribution of microtubules in non-seam cells, and their comparatively disorganized distribution in seam cells. Scale bar, $10 \mu \mathrm{m}$. Images are a courtesy from (Gally et al., 2009). (G) 2-fold stage embryo carrying DLG-1::RFP, a fluorescent reporter to visualize the DAC. Scale bar, $10 \mu \mathrm{m}$. (G') Camera lucida drawing of the CeAJ pattern represented in $(\mathbf{G})$, and $\left(\mathbf{G}^{\prime}\right.$ ') 
cross-section through the embryo to highlight the positions of muscles (pink bars) and of CeHDs in the overlying part of the epidermis (green dots). (H) 3D representation of the epidermis (area boxed in brown on G", then flattened). All epidermal cells contain actin microfilaments and microtubules, but only dorsal and ventral epidermal cells contain intermediate filaments. In the dorsal and ventral epidermis, actin filaments form circumferential bundles, which are intermingled with MTs. Colocalisation experiments suggest that IFs overlap with MFs. Dorsal and ventral cells establish CeHDs $(C$. elegans hemidesmosomes, also called fibrous organelles or FOs), which are junctions with the extracellular matrix that mechanically couple muscles to the cuticle. For the sake of clarity, several FO components were not drawn. Orientation on the compass: $\mathrm{D}=\mathrm{dorsal}, \mathrm{V}=\mathrm{ventral}, \mathrm{A}=\mathrm{anterior}, \mathrm{P}=$ posterior, $\mathrm{L}=\mathrm{left}$, R=right

\subsection{Actin and non-muscle myosin II}

The actomyosin cytoskeleton has prominent roles in various cellular and developmental processes, in particular to drive cell shape changes (Levayer and Lecuit, 2012). C. elegans has five closely related actin isoforms (ACT-1-5), but the precise distribution of these isoforms in non-muscle cells has not been systematically characterized. The non-muscle myosin II subunits include the heavy chains NMY-1 and NMY-2 (the latter is mostly required in early embryos), the regulatory light chain MLC-4 and the essential light chain MLC-5 (Shelton et al., 1999; Piekny et al., 2003; Gally et al., 2009). Although in other species phosphorylation of the heavy chain can play a prominent role (Vicente-Manzanares et al., 2009), all the proteins known to control myosin II activity in $C$. elegans epithelial cells appear to directly or indirectly target MLC-4 phosphorylation on residues MLC-4 ${ }^{\text {S18 }}$ and MLC-4 ${ }^{\mathrm{T} 19}$ (Gally et al., 2009).

In the epidermis, actin filaments display a clear anisotropic organization, being mostly circumferentially oriented. Starting at the 1.5-fold stage in dorsal and ventral epidermal cells, they forms parallel bundles of 5-10 individual filaments which are anchored to CeAJs and associated with non-muscle myosin below the furrows of the embryonic sheath (Figure 4A-B). In lateral seam cells, actin filaments are associated with high levels of non-muscle myosin II foci, but do not appear as tightly anchored to junctions as in dorsal/ventral cells, and probably remain individualized (Costa et al., 1998; Gally et al., 2009) (Figs. 4C-D). Within the dorsal and ventral epidermal cells, the specific molecular composition, the organization, and the polarity of filaments within bundles has not been established. In particular, it is not known whether actin polymerizes as long filaments running from one dorsal-seam $\mathrm{CeAJ}$ to the other, whether they run from one CeAJ to a hemidesmosome, or whether they make several short intermingled filaments of similar or opposite polarity. The occurrence of apparent actin bundle discontinuities at the level of hemidesmosomes in some backgrounds could indicate that hemidesmosomes represent an intermediate anchoring structure between CeAJs (arrows in Figure 5A). Actomyosin in seam cells represents the important driving force until the embryos reach the length two-fold (Priess and Hirsh, 1986; Piekny et al., 2003; Gally et al., 2009). 


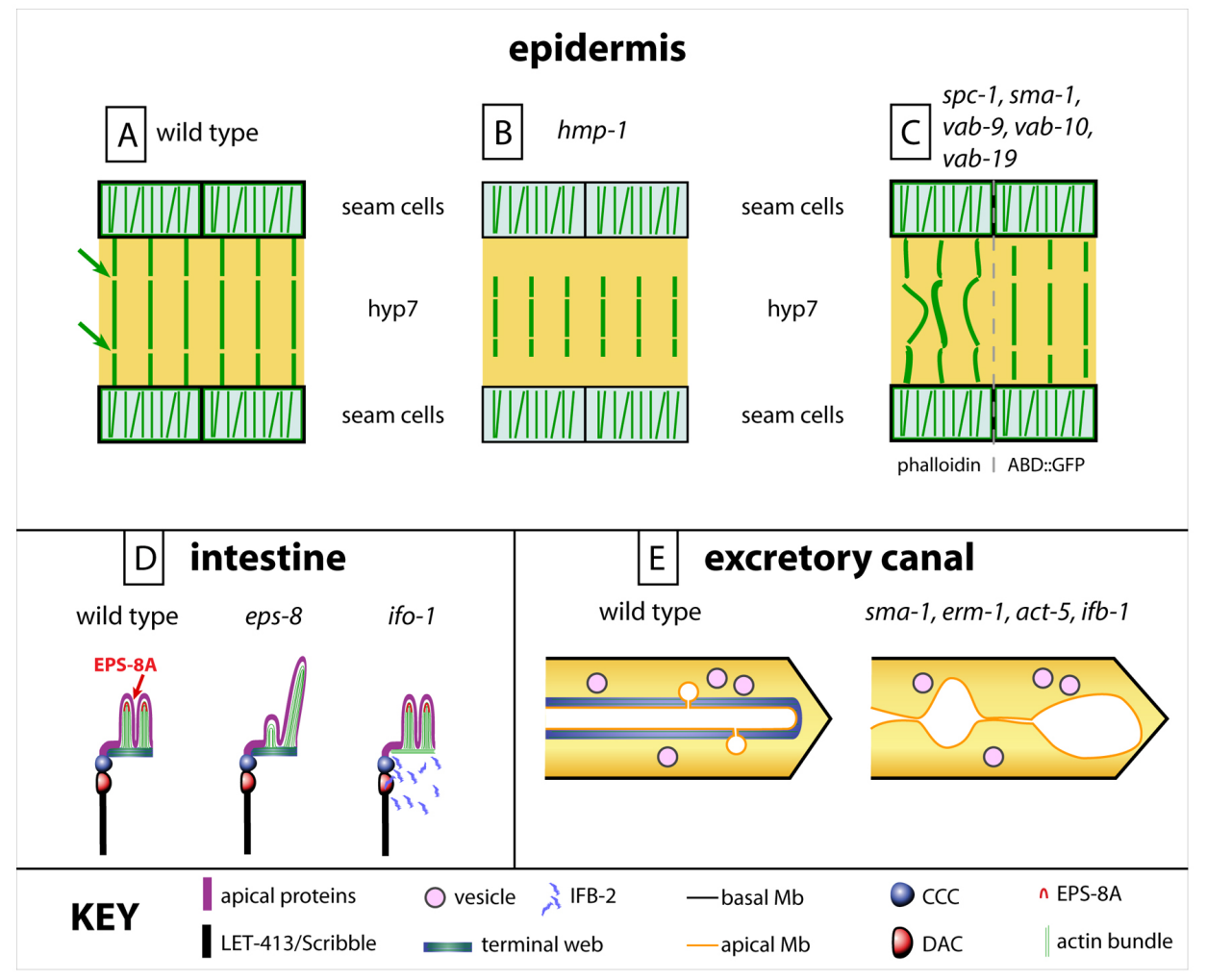

Figure 5. Anchoring of actin microfilaments. (A) Flat-mount representation of the dorsal half of an embryo, with seam cells (light blue) and the main dorsal epidermal syncytium hyp7 (dark yellow; anterior to the left, posterior to the right). Circumferential actin bundles in dorsal cells (vertical green lines) are anchored to the CCC (black lines); note the exaggerated interruption at the expected position of CeHDs (arrows), which has been observed only in certain conditions (Maiden et al., 2013). In seam cells, actin filaments look less organized and are probably not anchored to the CeAJ (see Figure 4 A-B). (B) In hmp-1 or hmp-2 mutants, actin bundles are not attached to the CeAJ; due to morphogenetic forces, they snap back to the middle of hyp7. (C) Actin filaments are significantly disorganized in mutants for the CCC component VAB-9, the apical spectrin SPC-1/SMA-1, the FO components VAB-19 and VAB-10, the regulatory actomyosin proteins LET-502 and MLC-4; however the extent of disorganization appears more severe after phalloidin staining (left moiety), compared to when seen with an actin-binding protein fused to GFP (right moiety). (D) Enlarged view of the intestinal lumen and brush border in wild-type animals (left), showing the localization of EPS-8A (red), which binds actin barbed ends through a novel domain found at its C-terminus, and of the actin-rich and IFB-2-rich terminal web at the basis of microvilli. In larvae lacking the EPS-8A isoform (middle), microvilli have irregular sizes and orientations or can be missing. In larvae lacking the intermediate filament and actin organizer IFO-1, the terminal web is strongly affected leading to lumen narrowing (not represented), IFB-2 aggregates and partial actin loss. (E) Representation of the excretory canal longitudinal section, with its so-called terminal web electron dense structure enriched in actin, actin-anchoring proteins (ERM-1, SMA-1) and intermediate filaments (IFA-2/3 and IFB-1). In the absence of ERM-1, SMA-1, ACT-5 or IFB-1, cysts develop, highlighting the importance of a terminal web in maintaining a regular lumen diameter in tubular organs.

\subsection{Actin dynamics}

The previous section was presenting a static vision of actin filaments as they can be observed in two-fold embryos and beyond. The mechanisms controlling the establishment of the two-fold pattern in dorsal/ventral cells, and even in seam cells, are not understood. Given that actin filaments are overall oriented along the circumference, it suggests either the existence of a planar polarity cue, or else of mechanical cues. The observation that actin remains almost normal in an $\mathrm{mlc}-4 /$ myosin regulatory light chain mutant and in a let-502/Rho-kinase mutant argue that mechanical tension alone (exerted by the actomyosin contractile system) cannot play a major role (Gally et al., 2009).

On the other hand, studies of ventral enclosure have uncovered several proteins controlling actin dynamics during the early phase of cell migration. In particular, Martha Soto and her collaborators dissected the role of the WAVE and Arp2/3 complexes in early aspects of actin assembly (Patel et al., 2008; Bernadskaya et al., 2012; Patel and Soto, 2013) (for details about the composition of these complexes, see Rotty et al., 2013). They found that the Ephrin receptor VAB-1, the Slit receptor SAX-3, and the Netrin receptor UNC-40 provide polarizing cues that activate those complexes. Specifically, UNC-40 appears to activate the small GTPase Rac, SAX-3 to promote assembly of the WAVE and Arp2/3 complexes leading to accumulation of branched actin at the ventral side of ventral cells, and VAB-1 to modulate subcellular localization of the WAVE complex (Bernadskaya et al., 2012). 
Embryos defective for the WAVE or ARP2/3 complexes accumulate less actin at the leading edge and fail to initiate migration (Soto et al., 2002; Sawa et al., 2003; Patel et al., 2008; Bernadskaya et al., 2012; Patel and Soto, 2013). Once migration is initiated, a distinct set of actin regulators promote filamentous, rather than branched, actin assembly and bundling. Specifically, combined absence of the Enabled homologue UNC-34 and of the WASP homologue WSP-1, strongly affects ventral migration presumably because actin does not form protrusive filaments (Withee et al., 2004; Sheffield et al., 2007).

\subsection{Actin anchoring}

In the epidermis, the CCC complex is essential to anchor the circumferential actin bundles, since lack of HMP-1/ $\alpha$-catenin or HMP-2/ $\beta$-catenin causes them to detach from the CeAJ (Costa et al., 1998) (Figure 5B). Consistent with the observation that drugs inhibiting actin polymerization prevent embryonic elongation (Gally et al., 2009), hmp-1 and hmp-2 mutations also block elongation (Priess and Hirsh, 1986). Furthermore, loss of several proteins associated with the CCC, such as JAC-1/p120-catenin, UNC-94/tropomodulin, the MAGuK homologues ZOO-1 and MAGI-1, enhances the elongation defect of a weak hmp-l mutation in part by weakening the anchoring of actin bundles to the CCC (Pettitt et al., 2003; Lockwood et al., 2008; Cox-Paulson et al., 2012; Lynch et al., 2012). As discussed above, UNC-94/tropomodulin homologue is not affecting anchoring in a direct way, but through its pointed-end capping function to stabilize junctional actin in a process that still has to be further defined (Cox-Paulson et al., 2012). The presence of redundant adhesion systems in C. elegans has made it possible to separate the actin anchoring and the cell-cell adhesion functions of the CCC.

Other proteins required to ensure the regular spacing of actin bundles include $\alpha$-spectrin $/ \beta_{\mathrm{H}}$-spectrin dimers, as well as the actin-binding proteins VAB-10 and EPS-8 associated with hemidesmosomes/fibrous organelles (see Figure 5C) (Norman and Moerman, 2002; Bosher et al., 2003; Ding et al., 2003). Interestingly, super-resolution microscopy established that the mammalian spectrin tetramer forms a ruler that helps to evenly space, by $180 \mathrm{~nm}$, actin rings found along axons (Xu et al., 2013); of note, the $\beta_{\mathrm{H}}$-spectrin of $C$. elegans is 1.6 times larger than the $\beta I V$-spectrin of mammalian axons, and the spacing of C. elegans circumferential actin bundles is $350 \mathrm{~nm}$. Also of note, authors relying on phalloidin staining to characterize actin defects have observed more severe defects than those relying on a GFP linked to the actin-binding domain of VAB-10 or SMA-1, but it is not entirely clear which method is more faithful. Phalloidin staining, which requires chemical fixation, might increase anchoring defects, whereas an actin-binding domain might partially stabilize actin filaments and alleviate the defects.

In the intestine, actin microfilaments are enriched at the lumen and in microvilli (Leung et al., 1999; Van Fürden et al., 2004) (Figure 5D). The Ezrin-Radixin-Moesin homologue ERM-1, together with SMA- $1 / \beta_{\mathrm{H}}$-spectrin, act as scaffolding proteins to anchor actin filaments at the lumen and ensure proper lumen formation (Göbel et al., 2004; Van Fürden et al., 2004). In particular, strong RNAi against erm-l causes a severe reduction of apical microfilaments and gut lumen constrictions (see above). Although ERM-1 is expressed in other epithelia, it only appears essential for the development of epithelia not lined by a cuticle (Göbel et al., 2004; Van Fürden et al., 2004). ERM-1 and SMA-1 play a similar role in the excretory canal, where they maintain the width of the lumen (Göbel et al., 2004, Van Fürden et al., 2004) (Figure 5E). Within brush borders actin forms long bundles, which are capped at their barbed-end by EPS-8A, the long isoform of the C. elegans homologue of the epidermal growth factor receptor substrate Eps8. EPS-8A is localized at the tips of the brush border intestinal microvilli (Croce et al., 2004) (Figure 5D). Its loss of function causes enlargement of the gut lumen, occasionally leading to larval lethality (Figure 5D).

\subsection{Spectrin network}

An important, though less discussed skeletal component is the spectrin network. Spectrins are long, flexible skeletal proteins that form hetero-tetramers, consisting of two $\alpha$ and two $\beta$ subdomains. They are localized directly under the cell membrane through proteins such as ankyrin, band4.1, and various ion channels or transporters (Bennett and Healy, 2009). The numerous spectrin repeats present in each subunit can change conformation under stress, which presumably confers the viscoelastic properties of erythrocytes and their ability to deform (Bennett and Healy, 2009). C. elegans contains three spectrins: $\beta_{\mathrm{H}}$-spectrin/SMA-1, localized apically, $\beta_{\mathrm{G}}$-spectrin/ UNC-70, localized basolaterally, and $\alpha$-spectrin/SPC-1, localized both apical and basolateral in epidermal and intestinal cells. Although their precise molecular function remains to be defined, it is clear that SMA-1 and SPC-1 are essential for embryonic morphogenesis, and for the regular distribution of actin bundles in dorsal and ventral epidermal cells (McKeown et al., 1998; Norman and Moerman, 2002; Praitis et al., 2005). However, their contribution to the establishment or maintenance of polarity is unlikely (Hammarlund et al., 2000; Moorthy et al., 2000). As in Drosophila, they interact with the Moesin homologue ERM-1 to maintain lumen integrity in the excretory cell (see Section 5.2) (Göbel et al., 2004; Van Fürden et al., 2004; Laprise and Tepass, 2011; Khan et al., 2013). 


\subsection{Microtubules}

The role of microtubules in C. elegans epithelia remains poorly characterized. Whether they mostly function in transport or are necessary to define cell shape has to be elucidated. There are nine $\alpha$-tubulins (TBA-1-9) and six $\beta$-tubulins (TBB-1-6) in the C. elegans genome. Microtubules are oriented circumferentially in dorsal (hyp7) and ventral (P cells) epidermal cells, where they appear intermingled with actin microfilament bundles, but are less well organized in lateral seam cells (Priess and Hirsh, 1986; Costa et al., 1997) (Figure 4E-F). In the intestine, microtubules are enriched at the prospective lumen, and as mentioned earlier play a key role in establishing cell polarity (Leung et al., 1999; Feldman and Priess, 2012). Besides their role in cell polarity, epithelial microtubules are important for nuclear migration. Typically, nocodazole treatment to depolymerize microtubules affects cell intercalation and nuclear migration in dorsal epidermal hyp7 (Williams-Masson et al., 1998). More specifically, the molecular motors kinesin-1 and dynein are recruited to the nuclear envelope by the KASH protein UNC-83 (Meyerzon et al., 2009; Fridolfsson et al., 2010). Kinesin, composed of UNC-116 and KLC-2, provides the major motor activity to pull the nucleus towards the distal microtubule +-ends, whereas dynein fine-tunes the process by generating short backwards movements (Fridolfsson et al., 2010; Fridolfsson and Starr, 2010). Compared to other systems, for which a wealth of information is available (Suozzi et al., 2012; Brieher and Yap, 2013), the mechanisms controlling microtubule dynamics in C. elegans epithelia remains largely unclear. Two proteins have been described that could potentially control microtubule dynamics in the epidermis, the small GTPase EVL-20 (an Arl-type GTPase) and the spectraplakin VAB-10B, but their effects have not yet been characterized in detail (Antoshechkin and Han, 2002; Bosher et al., 2003; Kim et al., 2011).

\subsection{Intermediate filaments}

The C. elegans genome encodes eleven individual IFs (IFA-1-4, IFB-1-2, IFC-1-2, IFD-1-2, IFP-1), besides the nuclear lamins. These proteins are more related to nuclear lamins than to any other vertebrate cytoplasmic IFs. In vitro polymerization assays suggest that IFB- 1 forms obligate heteropolymers with IFA- 2 and IFA-3, reminiscent of the vertebrate keratin system (Karabinos et al., 2003). Expression studies and genetic analysis further suggest that IFB-1/IFA-3 is the major heteropolymer in the embryonic epidermis, whereas IFB-1/MUA-6 is critical in the larval epidermis (Hapiak et al., 2003; Karabinos, 2004; Woo et al., 2004), where they are core components of CeHDs $(C$. elegans hemidesmosomes, see Section 6.1) (Karabinos et al., 2004). In the pharynx, IFA-1 forms heteropolymers with IFB-1 and is essential for feeding, while in the intestine three out of the four intestinal IFs must be removed to affect feeding and survival (Karabinos et al., 2001; Karabinos et al., 2003; Bossinger et al., 2004; Karabinos, 2004). Finally, in the excretory cell, IFB-1, coupled with IFA-2 or IFA-3, together with the ERM-1/SMA-1/actin network (see Section 5.2), make a cytoskeletal web that maintains the width of the lumen during development (Karabinos et al., 2001; Kolotuev et al., 2013) (Figure 5E).

\subsection{Intermediate filament assembly and homeostasis}

Increasing evidence suggests that IF assembly and homeostasis requires posttranslational modifications such as sumoylation and phosphorylation (discussed separately in Section 6.3) (Herrmann et al., 2007; Godsel et al., 2008). Work in C. elegans was the first to establish that IF sumoylation controls proper IF assembly (Kaminsky et al., 2009). Sumoylation depends on the attachment of SUMO, a small ubiquitin-like modifier (Geiss-Friedlander and Melchior, 2007), which in C. elegans is encoded by the essential gene smo-1 (Jones et al., 2002; Broday et al., 2004). Broday and colleagues identified IFB-1 in a screen for sumoylation-targets, showing that in smo- 1 mutants the IFB-1 pattern collapsed, leading to the formation of ectopic filaments and aggregates in the epidermis (Kaminsky et al., 2009) (Figure 6B). The lack of SUMO or a mutation of residue IFB-1 ${ }^{\mathrm{K} 460}$ reduced the soluble IFB-1 cytoplasmic pool, decreasing in turn IF-turnover at hemidesmosomes (Kaminsky et al., 2009). Hence SUMO behaves as negative factor of intermediate filament assembly acting by sequestering IFB-1. 


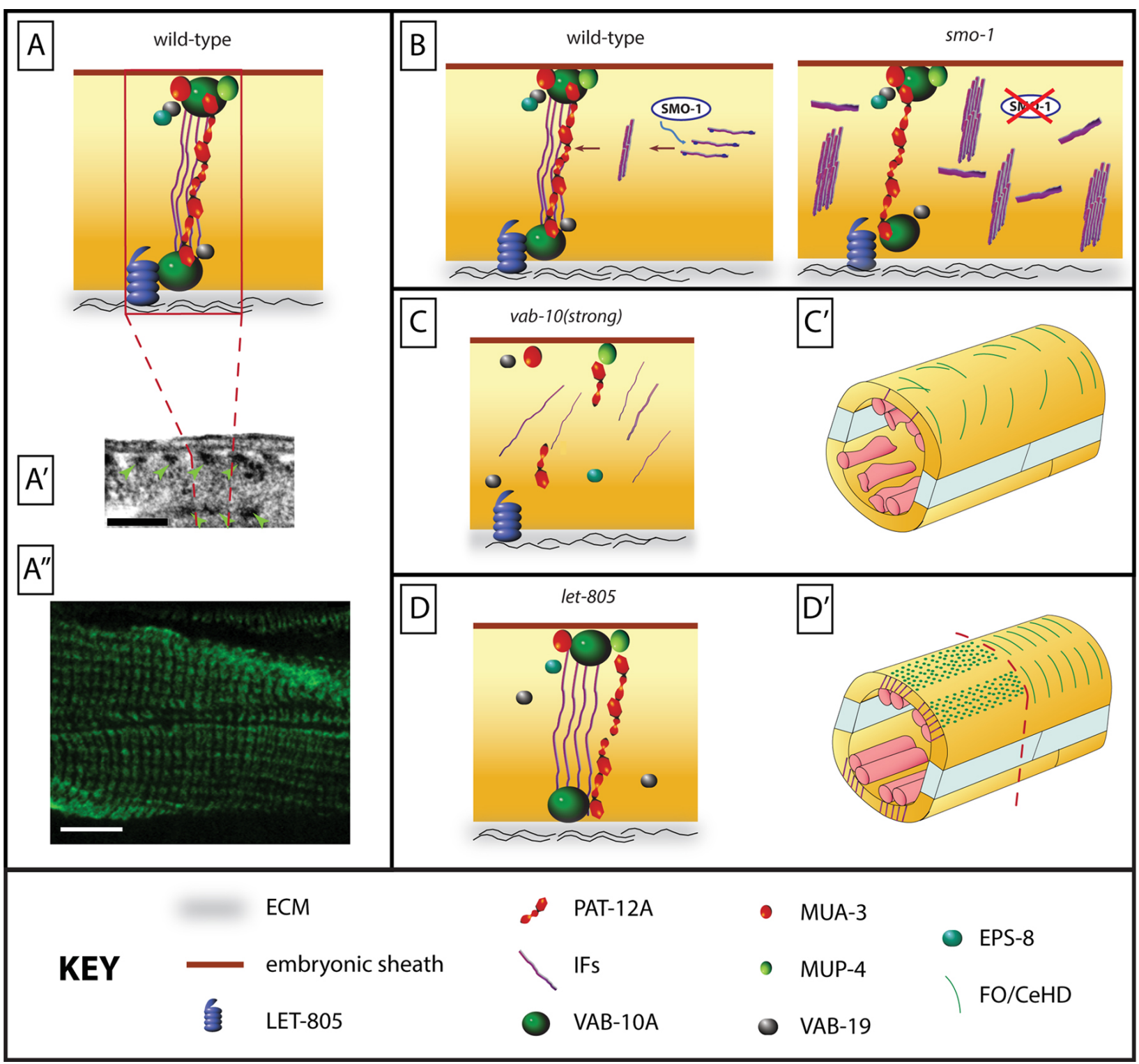

Figure 6. Intermediate filament assembly and Fibrous Organelle (FO) structure. (A) Sagittal view of the epidermis showing the structure of FOs. FOs correspond to two adhesion complexes each related to vertebrate hemidesmosomes and called CeHD (C. elegans hemidesmosome), which can be visualized as electron dense spots (A'; scale bar, $1 \mu \mathrm{m}$ ) bridged by intermediate filaments. (A"'; scale bar, $10 \mu \mathrm{m})$ Adult stained with MH5 mAb, showing the VAB-10A (FO component) pattern in adults. CeHDs are formed basally by the myotactin/LET-805 receptor or apically by the homologous MUA- 3 and MUP-4 receptors, the plectin/BPAGle-like VAB-10A, the ankyrin-repeat protein VAB-19/Kank, and the intermediate filament (IF) heterodimers IFB-1/IFA-2 or IFB-1/IFA-3. (B) Sagittal view showing that IF assembly requires their sumoylation by the SUMO protein SMO-1 to regulate the balance between short IF squiggles and longer IFs recruited to FOs. In a smo-1 mutant, squiggles predominate, reducing IF recruitment to FOs, leading to FO weakening. (C-C') Sagittal view (C) and cross-section view (C'; see Figure 4B" and 7A for wild-type reference) of a vab-10A mutant showing strongly disorganized/absent CeHDs; IFs, myotactin and VAB-19 have a very abnormal distribution or form aggregates. As a consequence, the epidermis can detach from the embryonic sheath (or the cuticle at later stages), muscles detach from the epidermis and collapse in the embryo. (D-D') Sagittal view (D) and cross-section view (D') showing a similar phenotype, albeit slightly less severe, in let-805/myotactin. CeHDs fail to evolve from foci to circumferential lines (left), or they stretch from much more along the circumference (right) inducing mis-localization of some CeHD components such as VAB-19.

Finally, work in $C$. elegans lead to the identification of a protein required for the assembly, organization and/or recruitment of IFs associated with the intestinal peri-lumenal region (Carberry et al., 2012). This histidineand polyproline-rich protein termed IFO-1 co-localizes with IFB-2 in the intestine. In ifo-1 mutants, IFB-2 disappears from the apical surface, and either makes cytoplasmic aggregates or becomes associated with the DAC component DLG-1 (Carberry et al., 2012) (Figure 5D). In addition, ifo-l mutants show reduced peri-apical levels of actin, and DAC interruptions when the Ezrin/Moesin homologue ERM-1 is also absent (Carberry et al., 2012). Hence, IFO-1 could tighten the linkage between IFs and the periapical cytoskeleton, probably by connecting it to 
actin. The protein PAT-12A (see below) might fulfill a role similar to IFO-1 in the epidermis; vertebrates might also harbor an IFO-1-like protein since keratin-8 down-regulation affects actin distribution in an ERM-dependent manner (Carberry et al., 2012).

Overall, IF analysis in C. elegans has revealed the regulatory role of posttranslational modifications, like phosphorylation and sumoylation, in IF assembly, established that IFs together with actin are key to maintain the integrity of the lumen in tubular organs.

\section{CeHDs and Fibrous organelles: cell-extracellular matrix junctions and mechanical coupling}

C. elegans dorsal and ventral epidermal cells possess a major apicobasal adhesion complex, called the fibrous organelle (FO). It mediates attachment of muscles to the cuticle, and which transmits cuticle deformation to mechanosensory touch neurons (Francis and Waterston, 1991). Similar structures are also found in the pharyngeal marginal cells. FOs look ultrastructurally, and to some extent molecularly and functionally, like two facing hemidesmosomes (HDs), and will be referred to as CeHD (C. elegans hemidesmosome) (Zhang and Labouesse, 2010). In vertebrates, HDs attach the basal layer of the epidermis to the basal lamina and are essential to anchor keratin filaments (Nievers et al., 1999; Litjens et al., 2006).

\subsection{Fibrous organelles resemble hemidesmosomes}

At the ultrastructural level, transmission electron microscopy reveals the presence of regularly spaced electron densities at the apical and basal plasma membranes of the ventral and dorsal epidermis, in regions overlying body wall, vulval, uterine, and anal muscles (Figure 6A-A') (Francis and Waterston, 1985; Francis and Waterston, 1991). These plaques, together with the dense array of filaments connecting them are reminiscent of the electron dense inner plaques present in vertebrate HDs.

At the molecular level, a central FO/CeHD component corresponds to IFB-1/IFA-3 and IFB-1/IFA-2 intermediate filaments (see Section 5.5) (Karabinos et al., 2001; Hapiak et al., 2003; Woo et al., 2004). Another key FO/CeHD component, VAB-10A, is a plakin equally homologous to plectin and BPAG1e, which connect keratin filaments to integrin and BPAG2 adhesion receptors within vertebrate HDs (Bosher et al., 2003). These giant cytolinker proteins can bind actin, intermediate filaments and/or microtubules, depending on the isoform (Sonnenberg and Liem, 2007; Suozzi et al., 2012). In effect, the vab-10 locus encodes two major isoform classes: the VAB-10A class has predicted actin- and IF-binding domains, whereas the VAB-10B class has predicted actinand microtubule-binding domains (Bosher et al., 2003; Kim et al., 2011). Immunogold staining localizes VAB-10A to a region enriched in filaments, while genetic experiments show that VAB-10A is required to anchor IFs (Figure 6C-C') (Bosher et al., 2003). Besides the plakin VAB-10A and the IFs (IFB-1/IFA-3 or IFB-1/IFA-2), other FO/CeHD components differ from vertebrate HDs.

The transmembrane adhesion molecules predicted to attach VAB-10A are MUA-3 and MUP-4 on the apical side of the epidermis, and myotactin/LET-805 on its basal side (Figure 6A) (Hresko et al., 1999; Bercher et al., 2001; Hong et al., 2001). These proteins are unrelated to integrins and BPAG2 (Table 1). The extracellular domains of MUA-3 and MUP-4 show weak similarity to matrilins, which are components of vertebrate tendons; this is intriguing because tendons are enriched in collagens like the cuticle, and FOs act as C. elegans tendons (Hahn and Labouesse, 2001). Other CeHD components include VAB-19 with four C-ter ankyrin repeats, which is homologous to the tumor suppressor Kank; VAB-19 interacts by yeast two-hybrid assay with the actin-capping protein EPS-8, another CeHD component (Ding et al., 2003; Ding et al., 2008) (Figure 6A). Another recently described CeHD component is PAT-12A, which is a nematode-specific protein bearing no homology to any known domain except for a potential coiled coil; PAT-12A can interact with the VAB-10 central common region by yeast two-hybrid assay (Hetherington et al., 2010). In vertebrates, laminin is the key extracellular matrix (ECM) required to assemble HDs (Nievers et al., 1999; Litjens et al., 2006). At the muscle-epidermis interface, a critical ECM protein for CeHD patterning is UNC-52, a perlecan homologue. Additional ECM proteins important for the late maintenance of CeHDs include the F-spondin homologue SPON-1, the ECM-modifying enzyme peroxidasin homologue PXN-2, and possibly laminin (Huang et al., 2003; Woo et al., 2008; Gotenstein et al., 2010). It is not entirely clear whether their effect is direct or reflects an indirect role through disorganization of muscles, which are essential for CeHD remodeling (see Section 6.3). On the apical side of the epidermis, the composition of the extracellular embryonic sheath present before cuticle deposition is not known, except for the likely presence of the Leu-rich repeat proteins SYM-1, EGG-6 and LET-4 (Mancuso et al., 2012). 
Last, but not least, at the functional level, akin to the skin blistering phenotype observed in patients compromised for an HD component (Nievers et al., 1999), mutations inactivating FO/CeHD components strongly affect epidermis integrity, causing it to detach from the cuticle on its apical side and from muscles on its basal side (Hresko et al., 1999; Bercher et al., 2001; Hong et al., 2001; Karabinos et al., 2001; Bosher et al., 2003; Ding et al., 2003; Hapiak et al., 2003; Karabinos et al., 2003; Woo et al., 2004; Ding et al., 2008; Hetherington et al., 2010). Muscle contractions are responsible for this phenotype since inhibiting their activity strongly reduces detachment (Bosher et al., 2003; Ding et al., 2003). The ensuing detachment prevents elongation and induces embryonic lethality, except in тиа-3 and тиа-6/ifa-2 mutants, which only affect larvae, suggesting that тиа-3 and тиа-6 fulfill a specialized role associated with the presence of a cuticle. The assembly of CeHDs and presumptive molecular function of the various CeHD components are discussed in Section 6.2.

\subsection{Assembly of FOs/CeHDs}

The process of CeHD assembly has been recently reviewed elsewhere (Zhang and Labouesse, 2010), and we will only summarize the main findings. As for adherens junctions and focal adhesions, the mechanisms controlling the initial CeHD assembly, and subsequently their maintenance and reorganization depend on different mechanisms. $\mathrm{FO} / \mathrm{CeHD}$ components initially form foci at the apical and basal epidermal membranes, which progressively evolve into short circumferential bands overlying muscles towards the end of elongation (Figure 7A-C) (Francis and Waterston, 1991; Zhang and Labouesse, 2010). They are not assembled when muscle precursors are ablated in early embryos (Hresko et al., 1999), although it is still unclear whether muscles simply stabilize FO/CeHD components, or induce their expression, much as Drosophila muscles induce the differentiation of tendon cells (Volk, 1999). 


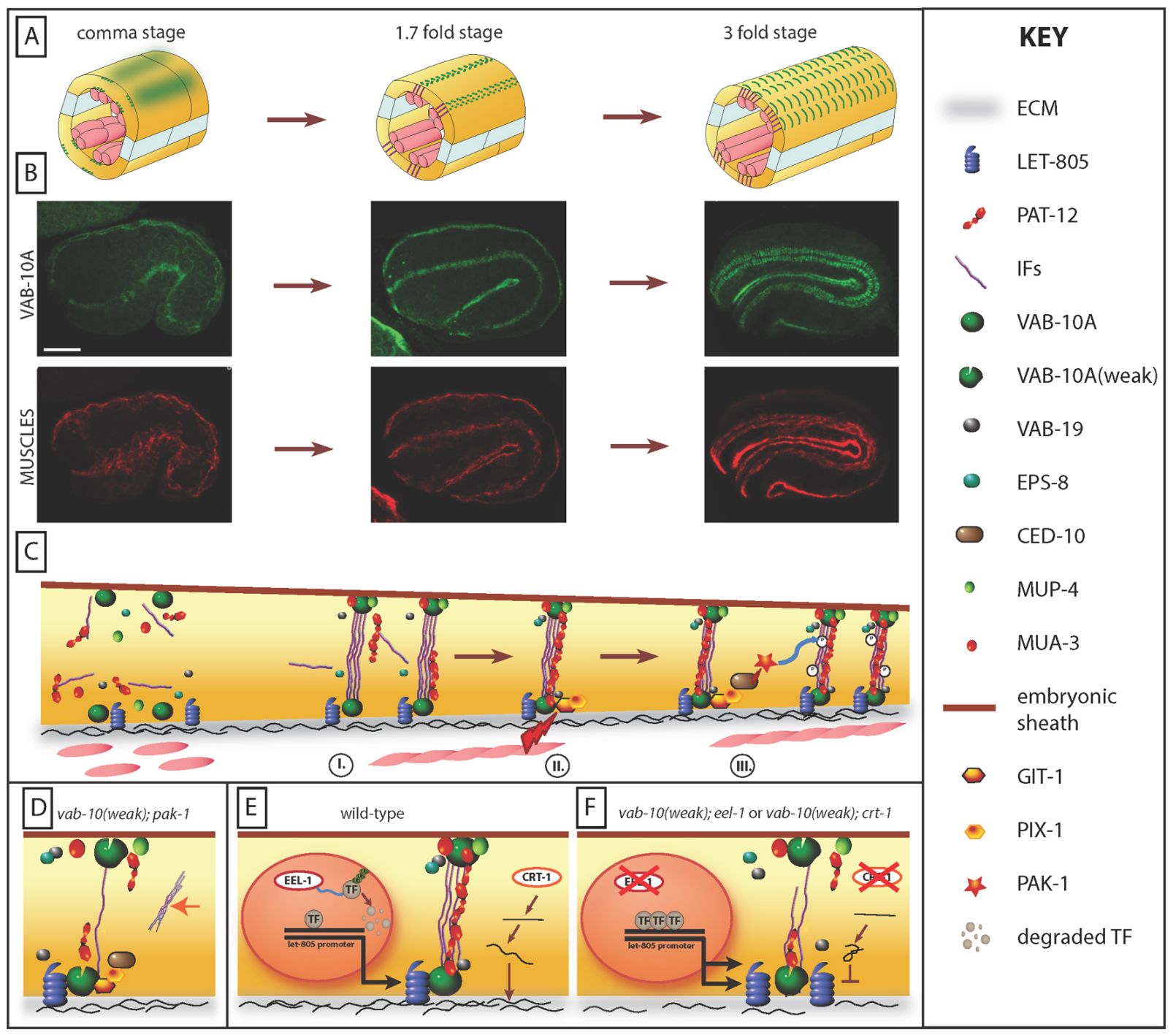

Figure 7. CeHD remodelling. (A) Schematized section of an embryo at three different stages, reflecting the evolution of CeHD and FO organisation (green). (B) Respective distribution of the CeHD protein VAB-10A and of a muscle component to illustrate those changes with time as muscles become active. Scale bar, $10 \mu \mathrm{m}$. (C) Illustration of FO and CeHD maturation. The trapezoidal shape of the epidermal cell represents that the epidermis becomes thinner along the apico-basal axis at the level of CeHDs during this process. First, CeHD components assemble apically and basally and progressively form puncta above muscles (I); muscle twitching induces a mechanotransduction process in the epidermis (II) whereby the proteins GIT-1, PIX-1 and CED-10 induce PAK-1 kinase activity and IFA-3 phosphorylation to promote FO maturation into short regularly-spaced circumferential bands above muscles (III). GIT-1, PIX-1 and PAK-1 are associated with CeHDs. (D) Affecting the mechanotransduction pathway in a weak vab-10A mutant induces the aggregation of ectopic IFs (orange arrow) and a weakening of CeHDs (sagittal view). (E) Remodelling of CeHDs is sensitive to the amount of LET-805 receptor and of UNC-52/Perlecan. The E3-ubiquitin ligase EEL-1 regulates the levels of some unknown nuclear factor (TF) that regulates let-805 expression; CRT-1/calreticulin helps fold and/or export UNC-52. (F) A two-fold increase of LET-805 as observed in eel-1 mutants, or a two-fold decrease of the ECM protein UNC-52/Perlecan levels as observed in crt-1 mutants compromises CeHD remodelling when in addition the VAB-10A protein is partially functional. 
The initial recruitment of FO components at the muscle-epidermis interface does not depend on other FO components, but their fine patterning does (Figure 6). A comparison of all published data (Zhang and Labouesse, 2010) suggests that the severity of FO/CeHD patterning defects is from most to less severe: $v a b-10 \mathrm{~A}>$ pat-12 > vab-19=eps-8 > let-805 > mиa-3 and mup-4 (Hetherington et al., 2010; Zhang and Labouesse, 2010). Typically, in the absence of VAB-10A, other components tend to get dispersed or to aggregate into abnormal bundles (Figure 6C-D). In the absence of PAT-12A the apical VAB-10A pool becomes strongly reduced, and IFs detach basally, suggesting that PAT-12A could help stabilize the IF-VAB-10A interaction apically (Hetherington et al., 2010). In the absence of VAB-19 or EPS-8, FO/CeHD fail to evolve from the initial punctate distribution to the banded distribution, and IFs occupy a larger area of the circumference (Ding et al., 2003; Ding et al., 2008). In the absence of LET-805, CeHDs reach a banded distribution that is larger over the circumference; a similar phenotype is also observed in spc-1, let-502, or mlc-4 mutants affecting the epidermal actomyosin cytoskeleton (Hresko et al., 1999; Norman and Moerman, 2002) (Figure 6D-D').

Maintenance of FOs/CeHDs also depends on VAB-10B, the VAB-10 isoform predicted to bind microtubules, whose distribution is intermingled with that of VAB-10A (Bosher et al., 2003). The reason for the progressive loss of FOs in vab-10B mutants is unclear, and may be due to a thickening of the epidermis, and/or a failure to maintain the integrity of the actin and microtubule cytoskeleton after the two-fold stage.

\subsection{Mechanotransduction and the reorganization of CeHDs}

As already alluded for AJs, there is increasing evidence that remodeling of cellular junctions depends on mechanical inputs (Riveline et al., 2001; Roca-Cusachs et al., 2012; Huveneers and de Rooij, 2013). This has also been clearly established to be the case for CeHDs as they evolve from a punctate pattern to a banded pattern (Zhang et al., 2011b).

C. elegans embryonic elongation consists of two main phases. Elongation until the two-fold stage is driven by the epidermal actomyosin contractile system acting mainly in seam cells; elongation beyond the two-fold stage requires muscle activity (see Epidermal morphogenesis). CeHD remodeling depends on muscle input, since it does not occur in strong muscle mutants (Zhang et al., 2011b). To account for this observation, Zhang and collaborators reasoned that muscles should provide a signal that would most likely be sensed at the level of CeHDs, which they found to be mechanical (Zhang et al., 2011b). Relying on a genetic screen, which identified several genes required for CeHD maturation (Zahreddine et al., 2010), they could define the pathway relaying this mechanical input (Zhang et al., 2011b). More specifically, they showed that muscle twitching is sensed by some CeHD components (yet to be identified), which then transform the mechanical input into a biochemical signaling pathway involving the GIT-1 adaptor protein, its binding partner PIX-1, a Rac-Guanine exchange factor, and the p21-activated kinase PAK-1, which are all associated with CeHDs (Zhang et al., 2011b) (Figure 7C). The best-defined cellular consequence of this pathway is to promote the recruitment of IFA-3 to hemidesmosomes during embryonic elongation through its phosphorylation (Zhang et al., 2011b). The recruitment process is defective when a mutation in git-1, pix-1, ced-10, or pak-1 is combined with a weak vab-10A mutant. (Figure 7D) Although it has not been determined whether PAK-1 directly phosphorylates IFA-3, Mass-Spec analysis and molecular studies indicate that IFA-3 ${ }^{\text {S470 }}$ could represent the residue targeted by PAK-1 (Zhang et al., 2011b). Since git-1, pix-1, and pak-1 mutants are less severe than strong pat muscle mutants, a second pathway should act in parallel, perhaps to promote junction remodeling and/or actin bundle shortening. This finding highlights that hemidesmosomes are not only structural entities but also as important mediators of signalization and mechanosensing. Interestingly, a dystroglycan-plectin complex may fulfill a related role in vertebrate alveolar epithelial cells in relaying mechanical stress (Takawira et al., 2011).

CeHD remodeling from punctate to banded pattern also appears very sensitive to the relative abundance of CeHD proteins, since it can be compromised when LET- 805 levels are doubled or UNC-52 levels are halved in the background of a weak vab-10A mutant (Zahreddine et al., 2010) (Figure 7E). Furthermore, the rate of elongation also matters since reducing it can partially relieve the defects observed in mutants with an excess of the CeHD component LET-805 (Zahreddine et al., 2010). Likewise, Ding, Chisholm, and coworkers found that loss of the $\beta_{\mathrm{H}}$-spectrin SMA-1 partially suppresses loss of the CeHD component VAB-19 (Ding et al., 2003).

Altogether work in C. elegans has very significantly contributed in a novel ways to our understanding of intermediate filament assembly, and on hemidesmosome remodeling under force.

\section{Conclusions and future directions}

The first version of this chapter, Epithelial junctions and attachments, predicted several main trends for the following few years: (1) making sense of the molecular relationships between the cytoskeletal networks, and (2) defining how adhesion complexes can modulate signaling during morphogenesis. The anticipated technical advances 
were potentially biochemical analysis through TAP-tag, and higher temporal imaging resolution in part to detect protein activity. Since then, we have indeed observed progress along those lines-a trend that should increase. Biochemical analysis has started in earnest (Kwiatkowski et al., 2010; Bernadskaya et al., 2011; Maiden et al., 2013), much as we have also observed improved time resolution (Zhang et al., 2011b), and the introduction of F-techniques (Cox-Paulson et al., 2012; Maiden et al., 2013). In effect, most progress over the past eight years has come from two areas: (1) a better understanding of the mechanisms maintaining cell polarity through trafficking, which has been made possible in part through genetic analysis and in part through elegant biochemistry (Zhang et al., 2011a; Khan et al., 2013); and (2) a better view at dynamic aspects of junction and cytoskeleton remodeling, which has been brought by imaging progress. We have most likely reached a plateau in terms of describing CeAJ and CeHD components. Future progress should now tackle the still mysterious issue of how microtubules are anchored, and more importantly disentangle the respective input of biochemical and mechanical signaling involved in junction maturation. Improved spatial and temporal imaging resolution and the use of methods to measure tension will be instrumental to achieve such goals.

\section{Table 1}

Table I. Genes encoding junctional or cytoskeletal components.

\begin{tabular}{|c|c|c|c|c|c|}
\hline Gene* & $\begin{array}{l}\text { Homology or } \\
\text { (domains) }\end{array}$ & $\begin{array}{l}\text { Expression } \\
\text { pattern }\end{array}$ & $\begin{array}{l}\text { Subcellular } \\
\text { localization }\end{array}$ & Phenotype & Reference \\
\hline$h m r-1$ & E-cadherin & ep., int., Pha. & $\mathrm{CeAJ}$ & $\begin{array}{l}\text { Emb; ventral } \\
\text { enclosure def. }\end{array}$ & $\begin{array}{l}\text { (Costa et al., } \\
\text { 1998; Raich et al., } \\
\text { 1999) }\end{array}$ \\
\hline hmp-1 & $\alpha$-catenin & ep., int., Pha. & $\mathrm{CeAJ}$ & $\begin{array}{l}\text { Emb; elongation } \\
\text { def. }\end{array}$ & $\begin{array}{l}\text { (Costa et al., } \\
\text { 1998; Raich et al., } \\
\text { 1999; Pettitt et al., } \\
\text { 2003) }\end{array}$ \\
\hline hmp-2 & $\beta$-catenin & ep., int., Pha. & $\mathrm{CeAJ}$ & $\begin{array}{l}\text { Emb; elongation } \\
\text { def. }\end{array}$ & $\begin{array}{l}\text { (Costa et al., } \\
\text { 1998; Raich et al., } \\
\text { 1999) }\end{array}$ \\
\hline$j a c-1$ & p120-catenin & ep., int., Pha. & $\mathrm{CeAJ}$ & $\begin{array}{l}\text { Enhancer of } \\
h m p-1(f e 4)\end{array}$ & $\begin{array}{l}\text { (Pettitt et al., } \\
\text { 2003) }\end{array}$ \\
\hline$v a b-9$ & BCMP1 claudin & ep., int., Pha. & $\mathrm{CeAJ}$ & Elongation def. & $\begin{array}{l}\text { (Simske et al., } \\
\text { 2003) }\end{array}$ \\
\hline$z o o-1$ & $\begin{array}{l}\text { ZO-1 (PDZ, SH3, } \\
\text { GuK) }\end{array}$ & ep., int., Pha. & $\mathrm{CeAJ}$ & $\begin{array}{l}\text { Enhancer of } \\
h m p-1(f e 4)\end{array}$ & $\begin{array}{l}\text { (Lockwood et al., } \\
2008)\end{array}$ \\
\hline apr-1 & APC & ep., int., Pha. & $\mathrm{CeAJ}$ & $\begin{array}{l}\text { Emb; ventral } \\
\text { enclosure def. }\end{array}$ & $\begin{array}{l}\text { (Hoier et al., } \\
\text { 2000) }\end{array}$ \\
\hline lad-1/sax-7 & $\begin{array}{l}\text { L1-CAM (FN3 + Ig } \\
\text { rep.) }\end{array}$ & $\begin{array}{l}\text { ubiq. up 350-c, all } \\
\text { epithelia }\end{array}$ & CeAJ & $\begin{array}{l}\text { Emb; elongation } \\
\text { def. }\end{array}$ & $\begin{array}{l}\text { (Chen et al., } \\
\text { 2001) }\end{array}$ \\
\hline magi-1 & Multi-PDZ & ep., int., Pha. & $\mathrm{CeAJ}$ & $\begin{array}{l}\text { Enhancer of } \\
h m p-1(f e 4)\end{array}$ & $\begin{array}{l}\text { (Stetak and } \\
\text { Hajnal, 2011; } \\
\text { Lynch et al., } \\
\text { 2012) }\end{array}$ \\
\hline afd-1 & $\begin{array}{l}\text { Afadin (RA, Dilute, } \\
\text { PDZ) }\end{array}$ & ep., int., Pha. & $\mathrm{CeAJ}$ & $\begin{array}{l}\text { Enhancer of } \\
h m p-1(f e 4)\end{array}$ & $\begin{array}{l}\text { (Lynch et al., } \\
\text { 2012) }\end{array}$ \\
\hline$d \lg -1$ & $\begin{array}{l}\text { Discs Large (PDZ, } \\
\text { SH3, GuK) }\end{array}$ & ep., int., Pha. & $\mathrm{CeAJ}$ & $\begin{array}{l}\text { Emb; elongation } \\
\text { def. }\end{array}$ & $\begin{array}{l}\text { (Bossinger et al., } \\
\text { 2001; Firestein } \\
\text { and Rongo, 2001; } \\
\text { Köppen et al., } \\
\text { 2001; McMahon } \\
\text { et al., 2001; } \\
\text { Segbert et al., } \\
\text { 2004) }\end{array}$ \\
\hline
\end{tabular}




\begin{tabular}{|c|c|c|c|c|c|}
\hline Gene* & \begin{tabular}{|l} 
Homology or \\
(domains)
\end{tabular} & $\begin{array}{l}\text { Expression } \\
\text { pattern }\end{array}$ & $\begin{array}{l}\text { Subcellular } \\
\text { localization }\end{array}$ & Phenotype & Reference \\
\hline ajm-1 & Novel (coiled coil) & ep., int., Pha. & $\mathrm{CeAJ}$ & $\begin{array}{l}\text { Emb; elongation } \\
\text { def. }\end{array}$ & $\begin{array}{l}\text { (Priess and Hirsh, } \\
\text { 1986; Bossinger } \\
\text { et al., 2001; } \\
\text { Köppen et al., } \\
\text { 2001) }\end{array}$ \\
\hline clc-1 & Classical claudin & Pha. & $\mathrm{CeAJ}$ & Permeability def. & $\begin{array}{l}\text { (Asano et al., } \\
\text { 2003) }\end{array}$ \\
\hline$c r b-1$ & Crumbs & int. & apical & None alone & $\begin{array}{l}\text { (Bossinger et al., } \\
\text { 2001; Segbert et } \\
\text { al., 2004) }\end{array}$ \\
\hline let -413 & Scribble (LRR, PDZ) & $\begin{array}{l}\text { ubiq. up 350-c, all } \\
\text { epithelia }\end{array}$ & basolateral & $\begin{array}{l}\text { Emb; elongation } \\
\text { def. }\end{array}$ & $\begin{array}{l}\text { (Legouis et al., } \\
\text { 2000; Legouis et } \\
\text { al., 2003; } \\
\text { Bossinger et al., } \\
\text { 2004) }\end{array}$ \\
\hline par-3 & PAR-3 (PDZ) & $\begin{array}{l}\text { Early embryo; } \\
\text { int., spermT. }\end{array}$ & apical & $\begin{array}{l}\text { Emb; gastrulation } \\
\text { def.; Ste }\end{array}$ & $\begin{array}{l}\text { (Aono et al., } \\
\text { 2004; Achilleos et } \\
\text { al., 2010; } \\
\text { Feldman and } \\
\text { Priess, 2012) }\end{array}$ \\
\hline par-6 & PAR-6 (PDZ) & $\begin{array}{l}\text { Early embryo; } \\
\text { int.; ep }\end{array}$ & apical & $\begin{array}{l}\text { Emb; gastrulation } \\
\text { def. }\end{array}$ & $\begin{array}{l}\text { (Totong et al., } \\
2007)\end{array}$ \\
\hline let-502 & $\begin{array}{l}\text { Rho-binding kinase } \\
\text { (kinase, } \mathrm{PH})\end{array}$ & Epidermis & $\mathrm{CeAJ}$ & $\begin{array}{l}\text { Ste; elongation } \\
\text { def. }\end{array}$ & $\begin{array}{l}\text { (Wissmann et al., } \\
\text { 1997; Piekny et } \\
\text { al., 2003; Diogon } \\
\text { et al., 2007; Gally } \\
\text { et al., 2009) }\end{array}$ \\
\hline rga-2 & $\begin{array}{l}\text { ARHGAP20 (PH, } \\
\text { RhoGAP) }\end{array}$ & Epidermis & Actin bundles & $\begin{array}{l}\text { elongation def., } \\
\text { rupture }\end{array}$ & $\begin{array}{l}\text { (Diogon et al., } \\
\text { 2007) }\end{array}$ \\
\hline mel-11 & MBP (ANK rep.) & Epidermis & $\mathrm{CeAJ}$ & $\begin{array}{l}\text { Ste; elongation } \\
\text { def., rupture }\end{array}$ & $\begin{array}{l}\text { (Wissmann et al., } \\
\text { 1997; Wissmann } \\
\text { et al., 1999; } \\
\text { Piekny et al., } \\
\text { 2003) }\end{array}$ \\
\hline git-1 & $\begin{array}{l}\text { Git1 (Arf-GAP, ANK, } \\
\text { GIT) }\end{array}$ & Non-seam ep. & $\mathrm{FO}$ & $\begin{array}{l}\text { Enhancer of } \\
\text { vab-10A(e698), } \\
\text { mild elongation } \\
\text { def. }\end{array}$ & $\begin{array}{l}\text { (Zhang et al., } \\
\text { 2011b) }\end{array}$ \\
\hline pix-1 & $\beta \mathrm{PIX}$ (SH3, Rho-GEF) & Non-seam ep. & FO & $\begin{array}{l}\text { Enhancer of } \\
\text { vab-10A }(e 698, \\
\text { mild elongation } \\
\text { def. }\end{array}$ & $\begin{array}{l}\text { (Zhang et al., } \\
\text { 2011b) }\end{array}$ \\
\hline pak-1 & p21-activated kinase & Epidermis & CeAJ, FO & unknown & $\begin{array}{l}\text { (Gally et al., } \\
\text { 2009; Zhang et } \\
\text { al., 2011b) }\end{array}$ \\
\hline erm-1 & $\begin{array}{l}\text { ezrin-radixin-moesin } \\
\text { (FERM domain) }\end{array}$ & most epithelia & apical & $\begin{array}{l}\text { Larval let; gut } \\
\text { constriction }\end{array}$ & $\begin{array}{l}\text { (Göbel et al., } \\
\text { 2004; Van Fürden } \\
\text { et al., 2004; Khan } \\
\text { et al., 2013) } \\
\end{array}$ \\
\hline eps-8 & EPS8 (PTB, SH3) & int., ep. & $\begin{array}{l}\text { tip of int. } \\
\text { microvilli, FO }\end{array}$ & $\begin{array}{l}\text { Emb; larval let; } \\
\text { ab. Int. brush } \\
\text { border; muscle } \\
\text { detach }\end{array}$ & $\begin{array}{l}\text { (Croce et al., } \\
\text { 2004; Ding et al., } \\
\text { 2008) }\end{array}$ \\
\hline
\end{tabular}




\begin{tabular}{|c|c|c|c|c|c|}
\hline Gene* & $\begin{array}{l}\text { Homology or } \\
\text { (domains) }\end{array}$ & $\begin{array}{l}\text { Expression } \\
\text { pattern }\end{array}$ & $\begin{array}{l}\text { Subcellular } \\
\text { localization }\end{array}$ & Phenotype & Reference \\
\hline sma-1 & $\beta_{\mathrm{H}}$-spectrin & ep., int., Pha., E.c. & apical & Elongation def. & $\begin{array}{l}\text { (McKeown et al., } \\
\text { 1998; Ding et al., } \\
\text { 2003; Fujita et al., } \\
\text { 2003; Göbel et } \\
\text { al., 2004; Praitis } \\
\text { et al., 2005) }\end{array}$ \\
\hline$s p c-1$ & $\beta_{H}$-spectrin & ubiq. & apical, basolateral & $\begin{array}{l}\text { Emb; elongation } \\
\text { def. }\end{array}$ & $\begin{array}{l}\text { (Moorthy et al., } \\
\text { 2000; Norman } \\
\text { and Moerman, } \\
\text { 2002) }\end{array}$ \\
\hline unc-70 & $\beta_{\mathrm{G}}$-spectrin & ubiq. & basolateral & Larval let & $\begin{array}{l}\text { (Hammarlund et } \\
\text { al., 2000; } \\
\text { Moorthy et al., } \\
\text { 2000) }\end{array}$ \\
\hline wve-1 & WAVE (WH2) & Most cells & basolateral & $\begin{array}{l}\text { Ventral enclosure } \\
\text { def. }\end{array}$ & (Patel et al., 2008) \\
\hline gex-2 & Sra1/p140/CYFIP & Most cells & basolateral & $\begin{array}{l}\text { Ventral enclosure } \\
\text { def. }\end{array}$ & $\begin{array}{l}\text { (Soto et al., 2002; } \\
\text { Patel et al., 2008; } \\
\text { Giuliani et al., } \\
\text { 2009) }\end{array}$ \\
\hline gex-3 & NAP1/HEM2/KETTE & Most cells & basolateral & $\begin{array}{l}\text { Ventral enclosure } \\
\text { def. }\end{array}$ & $\begin{array}{l}\text { (Soto et al., 2002; } \\
\text { Patel et al., 2008; } \\
\text { Giuliani et al., } \\
\text { 2009) }\end{array}$ \\
\hline abi-1 & $\mathrm{ABI}(\mathrm{SH} 3)$ & Most cells & basolateral & $\begin{array}{l}\text { Ventral enclosure } \\
\text { def. }\end{array}$ & $\begin{array}{l}\text { (Patel et al., 2008; } \\
\text { Giuliani et al., } \\
\text { 2009) }\end{array}$ \\
\hline unc-34 & Enabled & All epithelia & Cortical, CeAJ & $\begin{array}{l}\text { Enhancer of } \\
h m p-1(f e 4), \\
\text { Enhancer of } \\
w s p-1 \text { ventral } \\
\text { enclosure def. } \\
\end{array}$ & $\begin{array}{l}\text { (Withee et al., } \\
\text { 2004; Sheffield et } \\
\text { al., 2007) }\end{array}$ \\
\hline wsp-1 & N-WASP (PBD, WH2) & Not known & Not known & \begin{tabular}{|l|} 
Enhancer of \\
unc-34 ventral \\
enclosure def.
\end{tabular} & $\begin{array}{l}\text { (Withee et al., } \\
\text { 2004; Sheffield et } \\
\text { al., 2007) }\end{array}$ \\
\hline unc-94 & $\begin{array}{l}\text { Tropomodulin (pointed } \\
\text { end actin capping } \\
\text { protein) }\end{array}$ & Ep. & $\begin{array}{l}\text { Seam/non-seam } \\
\text { CeAJ }\end{array}$ & $\begin{array}{l}\text { Enhancer of } \\
h m p-1(f e 4)\end{array}$ & $\begin{array}{l}\text { (Cox-Paulson et } \\
\text { al., 2012) }\end{array}$ \\
\hline toca $-1 / 2$ & TOCA (F-BAR, SH3) & Most cells & $\begin{array}{l}\text { CeAJ and internal } \\
\text { vesicle }\end{array}$ & $\begin{array}{l}\text { Enhancer of } \\
\text { unc-34 ventral } \\
\text { enclosure def. }\end{array}$ & $\begin{array}{l}\text { (Giuliani et al., } \\
\text { 2009) }\end{array}$ \\
\hline ifa-1 & IF & $\begin{array}{l}\text { R., V. Ut., E.c., } \\
\text { Pha., P-I. v. }\end{array}$ & FO & Larval let & $\begin{array}{l}\text { (Dodemont et al., } \\
\text { 1994; Karabinos } \\
\text { et al., 2001; } \\
\text { Karabinos et al., } \\
\text { 2003) }\end{array}$ \\
\hline тиа-6/ifa-2 & IF & ep., R., V. Ut., & FO & $\begin{array}{l}\text { Larval let; muscle } \\
\text { detach. }\end{array}$ & \begin{tabular}{|l} 
(Dodemont et al., \\
1994; Karabinos \\
et al., 2001; \\
Hapiak et al., \\
2003; Karabinos \\
et al., 2003)
\end{tabular} \\
\hline
\end{tabular}




\begin{tabular}{|c|c|c|c|c|c|}
\hline Gene* & $\begin{array}{l}\text { Homology or } \\
\text { (domains) }\end{array}$ & $\begin{array}{l}\text { Expression } \\
\text { pattern }\end{array}$ & $\begin{array}{l}\text { Subcellular } \\
\text { localization }\end{array}$ & Phenotype & Reference \\
\hline if $a-3$ & IF & ep., R., P-I. v. & FO & $\begin{array}{l}\text { Emb; muscle } \\
\text { detach. }\end{array}$ & $\begin{array}{l}\text { (Dodemont et al., } \\
\text { 1994; Karabinos } \\
\text { et al., 2001; } \\
\text { Karabinos et al., } \\
\text { 2003; Woo et al., } \\
\text { 2004) }\end{array}$ \\
\hline$i f b-1$ & IF & $\begin{array}{l}\text { ep., R., V. Ut., } \\
\text { Pha., P-I. v. }\end{array}$ & FO & $\begin{array}{l}\text { Emb; muscle } \\
\text { detach. }\end{array}$ & $\begin{array}{l}\text { (Dodemont et al., } \\
\text { 1994; Karabinos } \\
\text { et al., 2001; } \\
\text { Karabinos et al., } \\
\text { 2003; Woo et al., } \\
\text { 2004) }\end{array}$ \\
\hline ifc-1 & IF & ep., R., Pha., int. & $\begin{array}{l}\text { FO in ep.?, CeAJ } \\
\text { in Pha., apical in } \\
\text { int. }\end{array}$ & Partial lethality & $\begin{array}{l}\text { (Karabinos et al., } \\
\text { 2001; Karabinos } \\
\text { et al., 2003; } \\
\text { Karabinos et al., } \\
\text { 2004) }\end{array}$ \\
\hline if $c-2$ & IF & Pha., int. & $\begin{array}{l}\text { cytoplasmic + } \\
\text { CeAJ }\end{array}$ & $\begin{array}{l}\text { weak lethality in } \\
\text { adults }\end{array}$ & $\begin{array}{l}\text { (Karabinos et al., } \\
\text { 2002; Karabinos } \\
\text { et al., 2004) }\end{array}$ \\
\hline $\begin{array}{l}\text { ifb-2, ifd-1, } \\
\text { ifd-2, ife-1 }\end{array}$ & IF & int. & apical & \begin{tabular}{|l|} 
\\
none alone/ \\
partial larval let in \\
triple knock-down
\end{tabular} & $\begin{array}{l}\text { Dodemont et al., } \\
\text { 1994; Karabinos } \\
\text { et al., 2001; } \\
\text { Karabinos et al., } \\
\text { 2003; Bossinger } \\
\text { et al., 2004; } \\
\text { Karabinos et al., } \\
\text { 2004) }\end{array}$ \\
\hline let -858 & $\begin{array}{l}\text { Novel (FN3 repeats, } \\
\text { TM) }\end{array}$ & $\begin{array}{l}\text { hyp syncytia, } \mathrm{P} \\
\text { cells, Pha. }\end{array}$ & FO & \begin{tabular}{|l|} 
Emb; muscle \\
detach
\end{tabular} & $\begin{array}{l}\text { (Hresko et al., } \\
\text { 1999) }\end{array}$ \\
\hline тир-4 & $\begin{array}{l}\text { Matrilin-like } \\
\text { (VWA+EGF rep.; TM) }\end{array}$ & $\begin{array}{l}\text { hyp syncytia, P } \\
\text { cells, Pha. }\end{array}$ & FO & $\begin{array}{l}\text { Emb; muscle } \\
\text { detach }\end{array}$ & $\begin{array}{l}\text { Gatewood and } \\
\text { Bucher, 1997; } \\
\text { Hong et al., 2001) }\end{array}$ \\
\hline тиа-3 & $\begin{array}{l}\text { Matrilin-like } \\
\text { (LDL+VWA+EGF } \\
\text { rep., TM) }\end{array}$ & $\begin{array}{l}\text { hyp syncytia, P } \\
\text { cells, Pha. }\end{array}$ & FO & muscle detach. & $\begin{array}{l}\text { (Plenefisch et al., } \\
\text { 2000; Bercher et } \\
\text { al., 2001) }\end{array}$ \\
\hline$v a b-19$ & Kank (ANK rep.) & $\begin{array}{l}\text { hyp syncytia, } \mathrm{P} \\
\text { cells, Pha. }\end{array}$ & FO & $\begin{array}{l}\text { Emb; muscle } \\
\text { detach. }\end{array}$ & (Ding et al., 2003) \\
\hline$v a b-10 A$ & $\begin{array}{l}\text { Plectin/BPAG1e (CH } \\
\text { rep., SPEC, PLEC rep.) }\end{array}$ & $\begin{array}{l}\text { hyp syncytia, P } \\
\text { cells, Pha. }\end{array}$ & FO & $\begin{array}{l}\text { Emb; muscle } \\
\text { detach. }\end{array}$ & $\begin{array}{l}\text { (Plenefisch et al., } \\
\text { 2000; Bosher et } \\
\text { al., 2003) }\end{array}$ \\
\hline$v a b-10 B$ & $\begin{array}{l}\text { MACF/BPAG1n (CH } \\
\text { rep., SPEC rep.; GAR) }\end{array}$ & $\begin{array}{l}\text { hyp syncytia, } \mathrm{P} \\
\text { cells, Pha., R., } \\
\text { int., muscles, NS }\end{array}$ & $\begin{array}{l}\text { between FO in } \\
\text { ep., apical in gut }\end{array}$ & $\begin{array}{l}\text { Emb; ep. } \\
\text { thickening }\end{array}$ & $\begin{array}{l}\text { (Bosher et al., } \\
\text { 2003; Kim et al., } \\
\text { 2011) }\end{array}$ \\
\hline \multicolumn{6}{|c|}{$\begin{array}{l}\text { *Genes are grouped according to their subcellular localization and/or function, limiting the information to epithelial } \\
\text { cells (see also Fig. 1). References are not exhaustive; for a more complete list see text. }\end{array}$} \\
\hline \multicolumn{6}{|c|}{$\begin{array}{l}\text { Abbreviations: ab., abnormal; ANK rep., ankyrin repeat; APC, Adenomatosis Polyposis Carcinoma; bind., binding; } \\
\text { Bioch., biochemical approach; CeAJ, C. elegans Apical Junction; Ced, Cell Death abnormal; CH, calponin } \\
\text { homology domain; def., defect; detach., detachment; Df, deficiency; DIL, SMART domain with no known } \\
\text { function; E.c., excretory cell; EGF rep., repeats found in the Epidermal Growth Factor; Emb, embryonic lethal; ep., } \\
\text { epidermis; e.s., epitope screening; F-BAR, extended Bin-Amphiphysin-Rvs; FERM, domain found in Band 4.1, }\end{array}$} \\
\hline
\end{tabular}




\begin{tabular}{|c|c|c|c|c|c|}
\hline Gene* & $\begin{array}{l}\text { Homology or } \\
\text { (domains) }\end{array}$ & $\begin{array}{l}\text { Expression } \\
\text { pattern }\end{array}$ & $\begin{array}{l}\text { Subcellular } \\
\text { localization }\end{array}$ & Phenotype & Reference \\
\hline \multicolumn{6}{|c|}{$\begin{array}{l}\text { ezrin, radixin, moesin proteins; FN3 rep., fibronectin type III repeats; GAR, growth arrest protein-2 related repeat } \\
\text { GIT, Helical motif in the GIT family; Homol., homology; IF, intermediate filament; Ig rep., immunoglobulin } \\
\text { superfamily repeat; int., intestine; LDL rep., Low Density Lipoprotein receptor A repeats; let, lethal; LRR, } \\
\text { Leucine-Rich repeat; mAb, monoclonal antibody; Mb, membrane; m.b., molecular biology; Mig, migration } \\
\text { defective; Pha., pharynx; PBD, p21-Rho- binding domain; PDZ, PSD-95/ Disc Large/ ZO-1 homology domain; } \\
\text { PH, pleckstrin homology domain; P-I. v., pharynx-intestinal valve; PLEC rep., plectin repeat; PM, plasma } \\
\text { membrane; PTB, phosphotyrosine-binding domain; R., rectum; rep., repeats; RA, Ras-association; RNAI, RNA } \\
\text { interference; SH3, src homology domain type 3; SPEC rep., spectrin repeat; spermT., spermatheca; TM, } \\
\text { transmembrane domain;; ut. Uterus; Vab, variably abnormal; V., vulva; VWA, von Willebrand Factor A repeats; } \\
\text { WH2, Wiskott Aldrich Homology region 2. }\end{array}$} \\
\hline
\end{tabular}

\section{Acknowledgements}

We thank past and present members of the Labouesse lab for lively and useful discussions, in particular Christelle Gally, Sophie Quintin, Vincent Hyenne, Shashi Kumar Suman and Thanh Vuong for critical reading of the manuscript. GP is supported by a Fellowship from the Universite de Strasbourg. This chapter was written in part while ML was on sabbatical, hosted by Stephan Grill at the MPI-CBG and MPI-PKS in Dresden, and ML thanks the support of a grant from the Max-Planck-Institute für Physik komplexer Systeme during this stay. Work in our laboratory is funded by institutional funds from the CNRS, INSERM and Hôpitaux Universitaires de Strasbourg, and by grants from the ERC (European Research Council) and ANR (Agence Nationale pour la Recherche) to ML.

\section{References}

Achilleos, A., Wehman, A.M., and Nance, J. (2010). PAR-3 mediates the initial clustering and apical localization of junction and polarity proteins during C. elegans intestinal epithelial cell polarization. Development 137, 1833-1842. Abstract Article

Adams, C.L., Chen, Y.T., Smith, S.J., and Nelson, W.J. (1998). Mechanisms of epithelial cell-cell adhesion and cell compaction revealed by high-resolution tracking of E-cadherin-green fluorescent protein. J. Cell Biol. 142, 1105-1119. Abstract

Antoshechkin, I., and Han, M. (2002). The C. elegans evl-20 gene is a homolog of the small GTPase ARL2 and regulates cytoskeleton dynamics during cytokinesis and morphogenesis. Dev. Cell. 2, 579-591. Abstract Article

Aono, S., Legouis, R., Hoose, W.A., and Kemphues, K.J. (2004). PAR-3 is required for epithelial cell polarity in the distal spermatheca of C. elegans. Development 131, 2865-284. Abstract Article

Asano, A., Asano, K., Sasaki, H., Furuse, M., and Tsukita, S. (2003). Claudins in Caenorhabditis elegans: their distribution and barrier function in the epithelium. Curr. Biol. 13, 1042-1046. Abstract Article

Bacaj, T., Tevlin, M., Lu, Y., and Shaham, S. (2008). Glia are essential for sensory organ function in C. elegans. Science 322, 744-747. Abstract Article

Balklava, Z., Pant, S., Fares, H., and Grant, B.D. (2007). Genome-wide analysis identifies a general requirement for polarity proteins in endocytic traffic. Nat. Cell Biol. 9, 1066-1073. Abstract Article

Baum, B., and Georgiou, M. (2011). Dynamics of adherens junctions in epithelial establishment, maintenance, and remodeling. J. Cell Biol. 192, 907-917. Abstract Article

Bennett, V., and Healy, J. (2009). Membrane domains based on ankyrin and spectrin associated with cell-cell interactions. Cold Spring Harb. Perspect. Biol. 1, a003012. Abstract Article

Bercher, M., Wahl, J., Vogel, B.E., Lu, C., Hedgecock, E.M., Hall, D.H., and Plenefisch, J.D. (2001). mua-3, a gene required for mechanical tissue integrity in Caenorhabditis elegans, encodes a novel transmembrane protein of epithelial attachment complexes. J. Cell Biol. 154, 415-426. Abstract Article 
Bernadskaya, Y.Y., Patel, F.B., Hsu, H.T., and Soto, M.C. (2011). Arp2/3 promotes junction formation and maintenance in the Caenorhabditis elegans intestine by regulating membrane association of apical proteins. Mol. Biol. Cell 22, 2886-2899. Abstract Article

Bernadskaya, Y.Y., Wallace, A., Nguyen, J., Mohler, W.A., and Soto, M.C. (2012). UNC-40/DCC, SAX-3/Robo, and VAB-1/Eph polarize F-actin during embryonic morphogenesis by regulating the WAVE/SCAR actin nucleation complex. PLoS Genet. 8, e1002863. Abstract Article

Berry, K.L., Bulow, H.E., Hall, D.H., and Hobert, O. (2003). A C. elegans CLIC-like protein required for intracellular tube formation and maintenance. Science 302, 2134-2137. Abstract Article

Bosher, J.M., Hahn, B.S., Legouis, R., Sookhareea, S., Weimer, R.M., Gansmuller, A., Chisholm, A.D., Rose, A.M., Bessereau, J.L., and Labouesse, M. (2003). The Caenorhabditis elegans vab-10 spectraplakin isoforms protect the epidermis against internal and external forces. J. Cell Biol. 161, 757-768. Abstract Article

Bossinger, O., Fukushige, T., Claeys, M., Borgonie, G., and McGhee, J.D. (2004). The apical disposition of the Caenorhabditis elegans intestinal terminal web is maintained by LET-413. Dev. Biol. 268, 448-456. Abstract Article

Bossinger, O., Klebes, A., Segbert, C., Theres, C., and Knust, E. (2001). Zonula adherens formation in Caenorhabditis elegans requires dlg-1, the homologue of the Drosophila gene discs large. Dev. Biol. 230, 29-42. Abstract Article

Brieher, W.M., and Yap, A.S. (2013). Cadherin junctions and their cytoskeleton(s). Curr. Opin. Cell Biol. 25, 39-46. Abstract Article

Broday, L., Kolotuev, I., Didier, C., Bhoumik, A., Gupta, B.P., Sternberg, P.W., Podbilewicz, B., and Ronai, Z. (2004). The small ubiquitin-like modifier (SUMO) is required for gonadal and uterine-vulval morphogenesis in Caenorhabditis elegans. Genes Dev. 18, 2380-2391. Abstract Article

Carberry, K., Wiesenfahrt, T., Geisler, F., Stocker, S., Gerhardus, H., Uberbach, D., Davis, W., Jorgensen, E., Leube, R.E., and Bossinger, O. (2012). The novel intestinal filament organizer IFO-1 contributes to epithelial integrity in concert with ERM-1 and DLG-1. Development 139, 1851-1862. Abstract Article

Chabanel, A., Sung, K.L., Rapiejko, J., Prchal J.T., Palek, J., Liu, S.C., and Chien, S. (1989). Viscoelastic properties of red cell membrane in hereditary elliptocytosis. Blood 73, 592-595. Abstract

Chanal, P., and Labouesse, M. (1997). A screen for genetic loci required for hypodermal cell and glial-like cell development during Caenorhabditis elegans embryogenesis. Genetics 146, 207-226. Abstract

Chen, L., Ong, B., and Bennett, V. (2001). LAD-1, the Caenorhabditis elegans L1CAM homologue, participates in embryonic and gonadal morphogenesis and is a substrate for fibroblast growth factor receptor pathway-dependent phosphotyrosine-based signaling. J. Cell Biol. 154, 841-855. Abstract Article

Chisholm, A.D., and Hardin, J. Epidermal morphogenesis (December 01, 2005), WormBook, ed. The C. elegans Research Community, WormBook, doi/10.1895/wormbook.1.35.1, http://www.wormbook.org.

Costa, M., Draper, B.W., and Priess, J.R. (1997). The role of actin filaments in patterning the Caenorhabditis elegans cuticle. Dev. Biol. 184, 373-384. Abstract Article

Costa, M., Raich, W., Agbunag, C., Leung, B., Hardin, J., and Priess, J.R. (1998). A putative catenin-cadherin system mediates morphogenesis of the Caenorhabditis elegans embryo. J. Cell Biol. 141, 297-308. Abstract Article

Cox-Paulson, E.A., Walck-Shannon, E., Lynch, A.M., Yamashiro, S., Zaidel-Bar, R., Eno, C.C., Ono, S., and Hardin, J. (2012). Tropomodulin protects $\alpha$-catenin-dependent junctional-actin networks under stress during epithelial morphogenesis. Curr. Biol. 22, 1500-1505. Abstract Article

Croce, A., Cassata, G., Disanza, A., Gagliani, M.C., Tacchetti, C., Malabarba, M.G., Carlier, M.F., Scita, G., Baumeister, R., and Di Fiore, P.P. (2004). A novel actin barbed-end-capping activity in EPS-8 regulates apical morphogenesis in intestinal cells of Caenorhabditis elegans. Nat. Cell Biol. 6, 1173-1179. Abstract Article 
Datta, A., Bryant, D.M., and Mostov, K.E. (2011). Molecular regulation of lumen morphogenesis. Curr. Biol. 21, R126-136. Abstract Article

Deborde, S., Perret, E., Gravotta, D., Deora, A., Salvarezza, S., Schreiner, R., and Rodriguez-Boulan, E. (2008). Clathrin is a key regulator of basolateral polarity. Nature 452, 719-723. Abstract Article

Ding, M., Goncharov, A., Jin, Y., and Chisholm, AD. (2003). C. elegans ankyrin repeat protein VAB-19 is a component of epidermal attachment structures and is essential for epidermal morphogenesis. Development 130, 5791-5801. Abstract Article

Ding, M., King, R.S., Berry, E.C., Wang, Y., Hardin, J., and Chisholm, A.D. (2008). The cell signaling adaptor protein EPS-8 is essential for C. elegans epidermal elongation and interacts with the ankyrin repeat protein VAB-19. PLoS One 3, e3346. Abstract Article

Diogon, M., Wissler, F., Quintin, S., Nagamatsu, Y., Sookhareea, S., Landmann, F., Hutter, H., Vitale, N., and Labouesse, M. (2007). The RhoGAP RGA-2 and LET-502/ROCK achieve a balance of actomyosin-dependent forces in C. elegans epidermis to control morphogenesis. Development 134, 2469-2479. Abstract Article

Dodemont, H., Riemer, D., Ledger, N., and Weber, K. (1994). Eight genes and alternative RNA processing pathways generate an unexpectedly large diversity of cytoplasmic intermediate filament proteins in the nematode Caenorhabditis elegans. EMBO J. 13, 2625-2638. Abstract

Elsum, I., Yates, L., Humbert, P.O., and Richardson, H.E. (2012). The Scribble-Dlg-Lgl polarity module in development and cancer: from flies to man. Essays Biochem. 53, 141-168. Abstract Article

Feldman, J.L., and Priess, J.R. (2012). A role for the centrosome and PAR-3 in the hand-off of MTOC function during epithelial polarization. Curr. Biol. 22, 575-582. Abstract Article

Firestein, B.L., and Rongo, C. (2001). DLG-1 is a MAGUK similar to SAP97 and is required for adherens junction formation. Mol. Biol. Cell 12, 3465-3475. Abstract Article

Fleming, T., Chien, S.C., Vanderzalm, P.J., Dell, M., Gavin, M.K., Forrester, W.C., and Garriga, G. (2010). The role of C. elegans Ena/VASP homolog UNC-34 in neuronal polarity and motility. Dev. Biol. 344, 94-106. Abstract Article

Folsch, H., Ohno, H., Bonifacino, J.S., and Mellman, I. (1999). A novel clathrin adaptor complex mediates basolateral targeting in polarized epithelial cells. Cell 99, 189-198. Abstract Article

Francis, G.R., and Waterston, R.H. (1985). Muscle organization in Caenorhabditis elegans: localization of proteins implicated in thin filament attachment and I-band organization. J. Cell Biol. 101, 1532-1549. Abstract Article

Francis, R., and Waterston, R.H. (1991). Muscle cell attachment in Caenorhabditis elegans. J. Cell Biol. 114, 465-479. Abstract Article

Fridolfsson, H.N., Ly, N., Meyerzon, M., and Starr, D.A. (2010). UNC-83 coordinates kinesin-1 and dynein activities at the nuclear envelope during nuclear migration. Dev. Biol. 338, 237-250. Abstract Article

Fridolfsson, H.N., and Starr, D.A. (2010). Kinesin-1 and dynein at the nuclear envelope mediate the bidirectional migrations of nuclei. J. Cell Biol. 191, 115-128. Abstract Article

Fujita, M., Hawkinson, D., King, K.V., Hall, DH., Sakamoto, H., and Buechner, M. (2003). The role of the ELAV homologue EXC-7 in the development of the Caenorhabditis elegans excretory canals. Dev. Biol. 256, 290-301. Abstract Article

Gally, C., Wissler, F., Zahreddine, H., Quintin, S., Landmann, F., and Labouesse, M. (2009). Myosin II regulation during C. elegans embryonic elongation: LET-502/ROCK, MRCK-1 and PAK-1, three kinases with different roles. Development 136, 3109-3119. Abstract Article

Gatewood, B.K., and Bucher, E.A. (1997). The mup-4 locus in Caenorhabditis elegans is essential for hypodermal integrity, organismal morphogenesis and embryonic body wall muscle position. Genetics 146, 165-183. Abstract 
Geiss-Friedlander, R., and Melchior, F. (2007). Concepts in sumoylation: a decade on. Nat. Rev. Mol. Cell Biol. 8, 947-956. Abstract Article

Giuliani, C., Troglio, F., Bai, Z., Patel, F.B., Zucconi, A., Malabarba, M.G., Disanza, A., Stradal, T.B., Cassata, G., Confalonieri, S., et al. (2009). Requirements for F-BAR proteins TOCA-1 and TOCA-2 in actin dynamics and membrane trafficking during Caenorhabditis elegans oocyte growth and embryonic epidermal morphogenesis. PLoS Genet. 5, e1000675. Abstract Article

Göbel, V., Barrett, Pha. L., Hall, D.H., and Fleming, J.T. (2004). Lumen morphogenesis in C. elegans requires the membrane-cytoskeleton linker erm-1. Dev. Cell 6, 865-873. Abstract Article

Godsel, L.M., Hobbs, R.P., and Green, K.J. (2008). Intermediate filament assembly: dynamics to disease. Trends Cell Biol. 18, 28-37. Abstract Article

Gotenstein, J.R., Swale, R.E., Fukuda, T., Wu, Z., Giurumescu, C.A., Goncharov, A., Jin, Y., and Chisholm, A.D. (2010). The C. elegans peroxidasin PXN-2 is essential for embryonic morphogenesis and inhibits adult axon regeneration. Development 137, 3603-3613. Abstract Article

Hahn, B.S., and Labouesse, M. (2001). Tissue integrity: Hemidesmosomes and resistance to stress. Curr. Biol. 11, R858-861. Abstract Article

Hammarlund, M., Davis, W.S., and Jorgensen, E.M. (2000). Mutations in $\beta$-spectrin disrupt axon outgrowth and sarcomere structure. J. Cell Biol. 149, 931-942. Abstract Article

Hapiak, V., Hresko, M.C., Schriefer, L.A., Saiyasisongkhram, K., Bercher, M., and Plenefisch, J. (2003). mиa-6, a gene required for tissue integrity in Caenorhabditis elegans, encodes a cytoplasmic intermediate filament. Dev. Biol. 263, 330-342. Abstract Article

Harris, K.P., and Tepass, U. (2008). Cdc42 and Par proteins stabilize dynamic adherens junctions in the Drosophila neuroectoderm through regulation of apical endocytosis. J. Cell Biol. 183, 1129-1143. Abstract Article

Herrmann, H., Bar, H., Kreplak, L., Strelkov, S.V., and Aebi, U. (2007). Intermediate filaments: from cell architecture to nanomechanics. Nat. Rev. Mol. Cell Biol. 8, 562-573. Abstract Article

Hetherington, S., Gally, C., Fritz, J.A., Polanowska, J., Reboul, J., Schwab, Y., Zahreddine, H., Behm, C., and Labouesse, M. (2010). PAT-12, a potential anti-nematode target, is a new spectraplakin partner essential for Caenorhabditis elegans hemidesmosome integrity and embryonic morphogenesis. Dev. Biol. 350, 267-278. Abstract Article

Hoier, E.F., Mohler, W.A., Kim, S.K., and Hajnal, A. (2000). The Caenorhabditis elegans APC-related gene apr-1 is required for epithelial cell migration and Hox gene expression. Genes Dev. 14, 874-886. Abstract Article

Hong, L., Elbl, T., Ward, J., Franzini-Armstrong, C., Rybicka, K.K., Gatewood, B.K., Baillie, D.L., and Bucher, E.A. (2001). MUP-4 is a novel transmembrane protein with functions in epithelial cell adhesion in Caenorhabditis elegans. J. Cell Biol. 154, 403-414. Abstract Article

Hresko, M.C., Schriefer, L.A., Shrimankar, P., and Waterston, R.H. (1999). Myotactin, a novel hypodermal protein involved in muscle-cell adhesion in Caenorhabditis elegans. J. Cell Biol. 146, 659-672. Abstract Article

Huang, C.C., Hall, D.H., Hedgecock, E.M., Kao, G., Karantza, V., Vogel, B.E., Hutter, H., Chisholm, A.D., Yurchenco, P.D., and Wadsworth, W.G. (2003). Laminin $\alpha$ subunits and their role in C. elegans development. Development 130, 3343-3358. Abstract Article

Humbert, P., Russell, S., and Richardson, H. (2003). Dlg, Scribble and Lgl in cell polarity, cell proliferation and cancer. Bioessays 25, 542-553. Abstract Article

Huveneers, S., and de Rooij, J. (2013). Mechanosensitive systems at the cadherin-F-actin interface. J. Cell Sci. 126, 403-413. Abstract Article 
Jones, D., Crowe, E., Stevens, T.A., and Candido, E.P. (2002). Functional and phylogenetic analysis of the ubiquitylation system in Caenorhabditis elegans: ubiquitin-conjugating enzymes, ubiquitin-activating enzymes, and ubiquitin-like proteins. Genome Biol. 3, RESEARCH0002. Abstract Article

Kaminsky, R., Denison, C., Bening-Abu-Shach, U., Chisholm, A.D., Gygi, S.P., and Broday, L. (2009). SUMO regulates the assembly and function of a cytoplasmic intermediate filament protein in C. elegans. Dev. Cell 17, 724-735. Abstract Article

Kang, J., Shin, D., Yu, J.R., and Lee, J. (2009). Lats kinase is involved in the intestinal apical membrane integrity in the nematode Caenorhabditis elegans. Development 136, 2705-2715. Abstract Article

Karabinos, A., Schünemann, J., and Weber, K. (2004). Most genes encoding cytoplasmic intermediate filament (IF) proteins of the nematode Caenorhabditis elegans are required in late embryogenesis. Eur. J. Cell Biol. 83, 457-468. Abstract Article

Karabinos, A., Schmidt, H., Harborth, J., Schnabel, R., and Weber, K. (2001). Essential roles for four cytoplasmic intermediate filament proteins in Caenorhabditis elegans development. Proc. Natl. Acad. Sci. U. S. A. 98, 7863-7868. Abstract Article

Karabinos, A., Schulze, E., Klisch, T., Wang, J., and Weber, K. (2002). Expression profiles of the essential intermediate filament (IF) protein A2 and the IF protein C2 in the nematode Caenorhabditis elegans. Mech. Dev. 117, 311-314. Abstract Article

Karabinos, A., Schulze, E., Schunemann, J., Parry, D.A., and Weber, K. (2003). In vivo and in vitro evidence that the four essential intermediate filament (IF) proteins A1, A2, A3 and B1 of the nematode Caenorhabditis elegans form an obligate heteropolymeric IF system. J. Mol. Biol. 333, 307-319. Abstract Article

Khan, L.A., Zhang, H., Abraham, N., Sun, L., Fleming, J.T., Buechner, M., Hall, D.H., and Gobel, V. (2013). Intracellular lumen extension requires ERM-1-dependent apical membrane expansion and AQP-8-mediated flux. Nat. Cell Biol. 15, 143-156. Abstract Article

Kim, H.S., Murakami, R., Quintin, S., Mori, M., Ohkura, K., Tamai, K.K., Labouesse, M., Sakamoto, H., and Nishiwaki, K. (2011). VAB-10 spectraplakin acts in cell and nuclear migration in Caenorhabditis elegans. Development 138, 4013-4023. Abstract Article

Knust, E., and Bossinger, O. (2002). Composition and formation of intercellular junctions in epithelial cells. Science 298, 1955-1959. Abstract Article

Kolotuev, I., Hyenne, V., Schwab, Y., Rodriguez, D., and Labouesse, M. (2013). A pathway for unicellular tube extension depending on the lymphatic vessel determinant Prox 1 and on osmoregulation. Nat. Cell Biol. 15, 157-168. Abstract Article

Köppen, M., Simske, J.S., Sims, P.A., Firestein, B.L., Hall, D.H., Radice, A.D., Rongo, C., and Hardin, J.D. (2001). Cooperative regulation of AJM-1 controls junctional integrity in Caenorhabditis elegans epithelia. Nat. Cell Biol. 3, 983-991. Abstract Article

Kramer, J.M. Basement membranes (September 1, 2005), WormBook, ed. The C. elegans Research Community, WormBook, doi/10.1895/wormbook.1.16.1, http://www.wormbook.org.

Kwiatkowski, A.V., Maiden, S.L., Pokutta, S., Choi, H.J., Benjamin, J.M., Lynch, A.M., Nelson, W.J., Weis, W.I., and Hardin, J. (2010). In vitro and in vivo reconstitution of the cadherin-catenin-actin complex from Caenorhabditis elegans. Proc. Natl. Acad. Sci. U. S. A. 107, 14591-14596. Abstract Article

Laprise, P., and Tepass, U. (2011). Novel insights into epithelial polarity proteins in Drosophila. Trends Cell Biol. 21, 401-408. Abstract Article

Legouis, R., Gansmuller, A., Sookhareea, S., Bosher, J.M., Baillie, D.L., and Labouesse, M. (2000). LET-413 is a basolateral protein required for the assembly of adherens junctions in Caenorhabditis elegans. Nat. Cell Biol. 2, 415-422. Abstract Article 
Legouis, R., Jaulin-Bastard, F., Schott, S., Navarro, C., Borg, J.P., and Labouesse, M. (2003). Basolateral targeting by leucine-rich repeat domains in epithelial cells. EMBO Rep. 4, 1096-1102. Abstract Article

Leibfried, A., Fricke, R., Morgan, M.J., Bogdan, S., and Bellaiche, Y. (2008). Drosophila Cip4 and WASp define a branch of the Cdc42-Par6-aPKC pathway regulating E-cadherin endocytosis. Curr. Biol. 18, 1639-1648. Abstract Article

Leung, B., Hermann, G.J., and Priess, J.R. (1999). Organogenesis of the Caenorhabditis elegans intestine. Dev. Biol. 216, 114-134. Abstract Article

Levayer, R., and Lecuit, T. (2012). Biomechanical regulation of contractility: spatial control and dynamics. Trends Cell Biol. 22, 61-81. Abstract Article

Litjens, S.H., de Pereda, J.M., and Sonnenberg, A. (2006). Current insights into the formation and breakdown of hemidesmosomes. Trends Cell Biol. 16, 376-383. Abstract Article

Lockwood, C., Zaidel-Bar, R., and Hardin, J. (2008). The C. elegans zonula occludens ortholog cooperates with the cadherin complex to recruit actin during morphogenesis. Curr. Biol. 18, 1333-1337. Abstract Article

Loveless, T., and Hardin, J. (2012). Cadherin complexity: recent insights into cadherin superfamily function in $C$. elegans. Curr. Opin. Cell Biol. 24, 695-701. Abstract Article

Lynch, A.M., Grana, T., Cox-Paulson, E., Couthier, A., Cameron, M., Chin-Sang, I., Pettitt, J., and Hardin, J. (2012). A genome-wide functional screen shows MAGI-1 is an L1CAM-dependent stabilizer of apical junctions in C. elegans. Curr. Biol. 22, 1891-1899. Abstract Article

Maiden, S.L., Harrison, N., Keegan, J., Cain, B., Lynch, A.M., Pettitt, J., and Hardin, J. (2013). Specific conserved C-terminal amino acids of Caenorhabditis elegans HMP-1/ $\alpha$-catenin modulate F-actin binding independently of vinculin. J. Biol. Chem. 288, 5694-5706. Abstract Article

Mancuso, V.P., Parry, J.M., Storer, L., Poggioli, C., Nguyen, K.C., Hall, DH., and Sundaram, M.V. (2012). Extracellular leucine-rich repeat proteins are required to organize the apical extracellular matrix and maintain epithelial junction integrity in C. elegans. Development 139, 979-990. Abstract Article

Mango, S.E. The C. elegans pharynx: a model for organogenesis (January 22, 2007), WormBook, ed. The C. elegans Research Community, WormBook, doi/10.1895/wormbook.1.129.1, http://www.wormbook.org.

McGhee, J.D. The C. elegans intestine (March 27, 2007), WormBook, ed. The C. elegans Research Community, WormBook, doi/10.1895/wormbook.1.133.1, http://www.wormbook.org.

McKeown, C., Praitis, V., and Austin, J. (1998). sma- 1 encodes a $\beta_{\mathrm{H}}$-spectrin homolog required for Caenorhabditis elegans morphogenesis. Development 125, 2087-2098. Abstract Article

McKinley, R.F., and Harris, T.J. (2012). Displacement of basolateral Bazooka/PAR-3 by regulated transport and dispersion during epithelial polarization in Drosophila. Mol. Biol. Cell 23, 4465-4471. Abstract Article

McMahon, L., Legouis, R., Vonesch, J.L., and Labouesse, M. (2001). Assembly of C. elegans apical junctions involves positioning and compaction by LET-413 and protein aggregation by the MAGUK protein DLG-1. J. Cell Sci. 114, 2265-2277. Abstract Article

Mellman, I., and Nelson, W.J. (2008). Coordinated protein sorting, targeting and distribution in polarized cells. Nat. Rev. Mol. Cell Biol. 9, 833-845. Abstract Article

Meyerzon, M., Fridolfsson, H.N., Ly, N., McNally, F.J., and Starr, D.A. (2009). UNC-83 is a nuclear-specific cargo adaptor for kinesin-1-mediated nuclear migration. Development 136, 2725-2733. Abstract Article

Moorthy, S., Chen, L., and Bennett, V. (2000). Caenorhabditis elegans $\beta-\mathrm{G}$ spectrin is dispensable for establishment of epithelial polarity, but essential for muscular and neuronal function. J. Cell Biol. 149, 915-930. Abstract Article 
Nance, J., Munro, E.M., and Priess, J.R. (2003). C. elegans PAR-3 and PAR-6 are required for apicobasal asymmetries associated with cell adhesion and gastrulation. Development 130, 5339-5350. Abstract

Nelson, W.J. (2003). Adaptation of core mechanisms to generate cell polarity. Nature 422, 766-774. Abstract

Nievers, M.G., Schaapveld, R.Q., and Sonnenberg, A. (1999). Biology and function of hemidesmosomes. Matrix Biol. 18, 5-17. Abstract Article

Norman, K.R., and Moerman, D.G. (2002). $\alpha$ spectrin is essential for morphogenesis and body wall muscle formation in Caenorhabditis elegans. J. Cell Biol. 157, 665-677. Abstract Article

Page, A.P. and Johnstone, I.L. The cuticle (March 19, 2007), WormBook, ed. The C. elegans Research Community, WormBook, doi/10.1895/wormbook.1.138.1, http://www.wormbook.org.

Patel, F.B., Bernadskaya, Y.Y., Chen, E., Jobanputra, A., Pooladi, Z., Freeman, K.L., Gally, C., Mohler, W.A., and Soto, M.C. (2008). The WAVE/SCAR complex promotes polarized cell movements and actin enrichment in epithelia during C. elegans embryogenesis. Dev. Biol. 324, 297-309. Abstract Article

Patel, F.B., and Soto, M.C. (2013). WAVE/SCAR promotes endocytosis and early endosome morphology in polarized C. elegans epithelia. Dev. Biol. 377, 319-332. Abstract Article

Pettitt, J., Cox, E.A., Broadbent, I.D., Flett, A., and Hardin, J. (2003). The Caenorhabditis elegans p120 catenin homologue, JAC-1, modulates cadherin-catenin function during epidermal morphogenesis. J. Cell Biol. 162, 15-22. Abstract Article

Piekny, A.J., Johnson, J.L., Cham, G.D., and Mains, P.E. (2003). The Caenorhabditis elegans nonmuscle myosin genes nmy- 1 and nmy-2 function as redundant components of the let-502/Rho-binding kinase and mel-11/myosin phosphatase pathway during embryonic morphogenesis. Development 130, 5695-5704. Abstract Article

Pilipiuk, J., Lefebvre, C., Wiesenfahrt, T., Legouis, R., and Bossinger, O. (2009). Increased IP3/Ca2+ signaling compensates depletion of LET-413/DLG-1 in C. elegans epithelial junction assembly. Dev. Biol. 327, 34-47. Abstract Article

Plenefisch, J.D., Zhu, X., and Hedgecock, E.M. (2000). Fragile skeletal muscle attachments in dystrophic mutants of Caenorhabditis elegans: isolation and characterization of the mua genes. Development 127, 1197-1207. Abstract

Podbilewicz, B., and White, J.G. (1994). Cell fusions in the developing epithelial of C. elegans. Dev. Biol. 161, 408-424. Abstract

Portereiko, M.F., and Mango, S.E. (2001). Early morphogenesis of the Caenorhabditis elegans pharynx. Dev. Biol. 233, 482-494. Abstract Article

Portereiko, M.F., Saam, J., and Mango, S.E. (2004). ZEN-4/MKLP1 is required to polarize the foregut epithelium. Curr. Biol. 14, 932-941. Abstract Article

Praitis, V., Ciccone, E., and Austin, J. (2005). SMA-1 spectrin has essential roles in epithelial cell sheet morphogenesis in C. elegans. Dev. Biol. 283, 157-170. Abstract Article

Priess, J.R., and Hirsh, D.I. (1986). Caenorhabditis elegans morphogenesis: the role of the cytoskeleton in elongation of the embryo. Dev. Biol. 117, 156-173. Abstract Article

Raich, W.B., Agbunag, C., and Hardin, J. (1999). Rapid epithelial-sheet sealing in the Caenorhabditis elegans embryo requires cadherin-dependent filopodial priming. Curr. Biol. 9, 1139-1146. Abstract Article

Rappleye, C.A., Paredez, A.R., Smith, C.W., McDonald, K.L., and Aroian, R.V. (1999). The coronin-like protein POD-1 is required for anterior-posterior axis formation and cellular architecture in the nematode Caenorhabditis elegans. Genes Dev. 13, 2838-2851. Abstract

Rauzi, M., Lenne, P.F., and Lecuit, T. (2010). Planar polarized actomyosin contractile flows control epithelial junction remodelling. Nature 468, 1110-1114. Abstract Article 
Riveline, D., Zamir, E., Balaban, N.Q., Schwarz, U.S., Ishizaki, T., Narumiya, S., Kam, Z., Geiger, B., and Bershadsky, A.D. (2001). Focal contacts as mechanosensors: externally applied local mechanical force induces growth of focal contacts by an mDia1-dependent and ROCK-independent mechanism. J. Cell Biol. 153, 1175-1186. Abstract Article

Roca-Cusachs, P., Iskratsch, T., and Sheetz, M.P. (2012). Finding the weakest link: exploring integrin-mediated mechanical molecular pathways. J. Cell Sci. 125, 3025-3038. Abstract Article

Rotty, J.D., Wu, C., and Bear, J.E. (2013). New insights into the regulation and cellular functions of the ARP2/3 complex. Nat. Rev. Mol. Cell Biol. 14, 7-12. Article

Sawa, M., Suetsugu, S., Sugimoto, A., Miki, H., Yamamoto, M., and Takenawa, T. (2003). Essential role of the $C$. elegans Arp2/3 complex in cell migration during ventral enclosure. J. Cell Sci. 116, 1505-1518. Abstract

Segbert, C., Johnson, K., Theres, C., van Fürden, D., and Bossinger, O. (2004). Molecular and functional analysis of apical junction formation in the gut epithelium of Caenorhabditis elegans. Dev. Biol. 266, 17-26. Abstract Article

Shafaq-Zadah, M., Brocard, L., Solari, F., and Michaux, G. (2012). AP-1 is required for the maintenance of apico-basal polarity in the C. elegans intestine. Development 139, 2061-2070. Abstract Article

Sheffield, M., Loveless, T., Hardin, J., and Pettitt, J. (2007). C. elegans Enabled exhibits novel interactions with N-WASP, Abl, and cell-cell junctions. Curr. Biol. 17, 1791-1796. Abstract Article

Shelton, C.A., Carter, J.C., Ellis, G.C., and Bowerman, B. (1999). The nonmuscle myosin regulatory light chain gene $m l c-4$ is required for cytokinesis, anterior-posterior polarity, and body morphology during Caenorhabditis elegans embryogenesis. J. Cell Biol. 146, 439-451. Abstract

Shibata, Y., Fujii, T., Dent, J.A., Fujisawa, H., and Takagi, S. (2000). EAT-20, a novel transmembrane protein with EGF motifs, is required for efficient feeding in Caenorhabditis elegans. Genetics 154, 635-646. Abstract

Simons, K., and Gerl, M.J. (2010). Revitalizing membrane rafts: new tools and insights. Nat. Rev. Mol. Cell Biol. 11, 688-699. Abstract Article

Simons, K., and van Meer, G. (1988). Lipid sorting in epithelial cells. Biochemistry 27, 6197-6202. Abstract Article

Simske, J.S., Köppen, M., Sims, P., Hodgkin, J., Yonkof, A., and Hardin, J. (2003). The cell junction protein VAB-9 regulates adhesion and epidermal morphology in C. elegans. Nat. Cell Biol. 5, 619-625. Abstract Article

Sonnenberg, A., and Liem, R.K. (2007). Plakins in development and disease. Exp. Cell Res. 313, 2189-2203. Abstract Article

Soto, M.C., Qadota, H., Kasuya, K., Inoue, M., Tsuboi, D., Mello, C.C., and Kaibuchi, K. (2002). The GEX-2 and GEX-3 proteins are required for tissue morphogenesis and cell migrations in C. elegans. Genes Dev. 16, 620-632. Abstract

Stetak, A., and Hajnal, A. (2011). The C. elegans MAGI-1 protein is a novel component of cell junctions that is required for junctional compartmentalization. Dev. Biol. 350, 24-31. Abstract Article

Suozzi, K.C., Wu, X., and Fuchs, E. (2012). Spectraplakins: master orchestrators of cytoskeletal dynamics. J. Cell Biol. 197, 465-475. Abstract Article

Takai, Y., Miyoshi, J., Ikeda, W., and Ogita, H. (2008). Nectins and nectin-like molecules: roles in contact inhibition of cell movement and proliferation. Nat. Rev. Mol. Cell Biol. 9, 603-615. Abstract Article

Takawira, D., Budinger, G.R., Hopkinson, S.B., and Jones, J.C. (2011). A dystroglycan/plectin scaffold mediates mechanical pathway bifurcation in lung epithelial cells. J. Biol. Chem. 286, 6301-6310. Abstract Article

Tepass, U. (2012). The apical polarity protein network in Drosophila epithelial cells: regulation of polarity, junctions, morphogenesis, cell growth, and survival. Annu. Rev. Cell Dev. Biol. 28, 655-685. Abstract Article 
Terns, R.M., Kroll-Conner, P., Zhu, J., Chung, S., and Rothman, J.H. (1997). A deficiency screen for zygotic loci required for establishment and patterning of the epidermis in Caenorhabditis elegans. Genetics 146, 185-206. Abstract

Thomas-Virnig, C.L., Sims, P.A., Simske, J.S., and Hardin, J. (2004). The inositol 1,4,5-trisphosphate receptor regulates epidermal cell migration in Caenorhabditis elegans. Curr. Biol. 14, 1882-1887. Abstract Article

Totong, R., Achilleos, A., and Nance, J. (2007). PAR-6 is required for junction formation but not apicobasal polarization in C. elegans embryonic epithelial cells. Development 134, 1259-1268. Abstract Article

Tsukita, S., Furuse, M., and Itoh, M. (1999). Structural and signalling molecules come together at tight junctions. Curr. Opin. Cell Biol. 11, 628-633. Abstract Article

Van Fürden, D., Johnson, K., Segbert, C., and Bossinger, O. (2004). The C. elegans ezrin-radixin-moesin protein ERM-1 is necessary for apical junction remodelling and tubulogenesis in the intestine. Dev. Biol. 272, 262-276. Abstract Article

Vasioukhin, V., Bauer, C., Yin, M., and Fuchs, E. (2000). Directed actin polymerization is the driving force for epithelial cell-cell adhesion. Cell 100, 209-219. Abstract Article

Vicente-Manzanares, M., Ma, X., Adelstein, R.S., and Horwitz, A.R. (2009). Non-muscle myosin II takes centre stage in cell adhesion and migration. Nat. Rev. Mol. Cell Biol. 10, 778-790. Abstract Article

Volk, T. (1999). Singling out Drosophila tendon cells: a dialogue between two distinct cell types. Trends Genet. 15, 448-453. Abstract Article

Walker, D.S., Ly, S., Lockwood, K.C., and Baylis, H.A. (2002). A direct interaction between IP(3) receptors and myosin II regulates IP(3) signaling in C. elegans. Curr. Biol. 12, 951-956. Abstract Article

White, E.A., and Glotzer, M. (2012). Centralspindlin: at the heart of cytokinesis. Cytoskeleton 69, 882-892. Abstract Article

Williams-Masson, E.M., Heid, P.J., Lavin, C.A., and Hardin, J. (1998). The cellular mechanism of epithelial rearrangement during morphogenesis of the Caenorhabditis elegans dorsal hypodermis. Dev. Biol. 204, 263-276. Abstract Article

Williams-Masson, E.M., Malik, A.N., and Hardin, J. (1997). An actin-mediated two-step mechanism is required for ventral enclosure of the C. elegans hypodermis. Development 124, 2889-2901. Abstract

Winter, J.F., Hopfner, S., Korn, K., Farnung, B.O., Bradshaw, C.R., Marsico, G., Volkmer, M., Habermann, B., and Zerial, M. (2012). Caenorhabditis elegans screen reveals role of PAR-5 in RAB-11-recycling endosome positioning and apicobasal cell polarity. Nat. Cell Biol. 14, 666-676. Abstract Article

Wissmann, A., Ingles, J., and Mains, P.E. (1999). The Caenorhabditis elegans mel-11 myosin phosphatase regulatory subunit affects tissue contraction in the somatic gonad and the embryonic epidermis and genetically interacts with the Rac signaling pathway. Dev. Biol. 209, 111-127. Abstract Article

Wissmann, A., Ingles, J., McGhee, J.D., and Mains, P.E. (1997). Caenorhabditis elegans LET-502 is related to Rho-binding kinases and human myotonic dystrophy kinase and interacts genetically with a homolog of the regulatory subunit of smooth muscle myosin phosphatase to affect cell shape. Genes Dev. 11, 409-422. Abstract Article

Withee, J., Galligan, B., Hawkins, N., and Garriga, G. (2004). Caenorhabditis elegans WASP and Ena/VASP proteins play compensatory roles in morphogenesis and neuronal cell migration. Genetics 167, 1165-1176. Abstract Article

Woo, W.M., Berry, E.C., Hudson, M.L., Swale, R.E., Goncharov, A., and Chisholm, A.D. (2008). The C. elegans F-spondin family protein SPON-1 maintains cell adhesion in neural and non-neural tissues. Development 135, 2747-2756. Abstract Article 
Woo, W.M., Goncharov, A., Jin, Y., and Chisholm, A.D. (2004). Intermediate filaments are required for C. elegans epidermal elongation. Dev. Biol. 267, 216-229. Abstract Article

$\mathrm{Xu}$, K., Zhong, G., and Zhuang, X. Actin, spectrin, and associated proteins form a periodic cytoskeletal structure in axons. Science 339, 452-456. Article

Zahreddine, H., Zhang, H., Diogon, M., Nagamatsu, Y., and Labouesse, M. (2010). CRT-1/calreticulin and the E3 ligase EEL-1/HUWE1 control hemidesmosome maturation in C. elegans development. Curr. Biol. 20, $322-327$. Abstract Article

Zhang, H., Abraham, N., Khan, L.A., Hall, D.H., Fleming, J.T., and Gobel, V. (2011a). Apicobasal domain identities of expanding tubular membranes depend on glycosphingolipid biosynthesis. Nat. Cell Biol. 13, 1189-1201. Abstract Article

Zhang, H., Kim, A., Abraham, N., Khan, L.A., Hall, D.H., Fleming, J.T., and Gobel, V. (2012). Clathrin and AP-1 regulate apical polarity and lumen formation during C. elegans tubulogenesis. Development 139, $2071-2083$. Abstract Article

Zhang, H., and Labouesse, M. (2010). The making of hemidesmosome structures in vivo. Dev. Dyn. 239, 1465-1476. Abstract Article

Zhang, H., Landmann, F., Zahreddine, H., Rodriguez, D., Koch, M., and Labouesse, M. (2011b). A tension-induced mechanotransduction pathway promotes epithelial morphogenesis. Nature 471, 99-103. Abstract Article 